\title{
Análise dos livros de geometria indicados nos cursos de licenciatura em matemática
}

\author{
An analysis of geometry books used on a Brazilian teaching certification program in \\ mathematics
}

\author{
Maridete Brito Cunha Ferreira \\ $\underline{\text { mbferreira@uneb.br }}$ \\ Saddo Ag Almouloud \\ saddoag@gmail.com
}

\begin{abstract}
Resumo
Este artigo tem como objetivo apresentar os resultados da análise de livros de geometria plana adotados em cursos de licenciatura em matemática. Especificamente, focalizamos nossa atenção nas tarefas relativas a provas e demonstrações envolvendo o conteúdo 'quadriláteros', nos livros selecionados. Diante da Teoria Antropológica do Didático, analisamos os livros escolhidos em termos de tarefa, técnica e bloco teóricotecnológico, investigando como os autores apresentam o método dedutivo e seus termos próprios e como é feito o estudo dos quadriláteros, tendo como foco as definições e as demonstrações. Nossa análise também foi fundamentada na tipologia de provas em matemática e na Teoria dos Registros de Representações Semióticas. Como procedimento metodológico, utilizamos a coleta e análise de dados bibliográficos. Os resultados do estudo mostram que, nos livros analisados, o tópico 'quadriláteros' é abordado de forma superficial e as propriedades são validadas por meio de provas conceituais. Os três livros desenvolvem o conteúdo 'quadriláteros' de forma semelhante, em que a abordagem dos conceitos e propriedades é direta, sem utilização de nenhum recurso que leve o aluno a fazer conjecturas. Em vez disso, procedem à formalização, seguida da resolução de problemas.
\end{abstract}

Palavras-chave: Prova e demonstração; Geometria plana; Licenciatura em matemática.

\begin{abstract}
This article reports the findings of an analysis of plane geometry textbooks used on a Brazilian undergraduate teaching certification program in mathematics. The investigation focused specifically on tasks involving proofs and demonstrations for quadrilaterals. Drawing on Chevallard's Anthropological Theory of the Didactic, the books were evaluated on tasks, techniques, and theoretical-technological elements. The books were also assessed on how the authors chose to introduce the deductive method and its specific terminology, and how the study of quadrilaterals was developed through the use of definitions and demonstrations. The analysis was also guided by the typology of mathematical proofs and Duval's Theory of Registers of Semiotic Representations. Three textbooks were the primary source of data for the analysis. In these books, quadrilaterals were addressed in a superficial manner, and the properties of these polygons were validated by means of conceptual proofs. Quadrilateral-related content was addressed similarly in all three books-i.e., presentation of concepts and properties was straightforward, devoid of resources that might encourage students to make conjectures, and limited to formalization, followed by problem resolution.
\end{abstract}

Keywords: Proofs and demonstrations; Plane geometry; Teaching certification in mathematics.

\section{Introdução}

Os resultados observados na revisão de literatura associados à nossa experiência nos permitem afirmar que a abordagem do método dedutivo na graduação é feita no sentido inverso em relação ao desenvolvimento desse método. Há indícios de que não está sendo 
permitido ao aluno construir a demonstração a partir de uma motivação que possa provocar sua descoberta. Diante dessa afirmação, sentimos a necessidade de investigar de que forma os livros de geometria, utilizados na licenciatura em matemática, estão abordando as demonstrações.

Neste artigo, apresentamos um recorte da tese de doutorado da primeira autora, discutindo os resultados da análise de livros de geometria plana adotados em cursos de licenciatura em matemática. Especificamente, focalizamos nossa atenção nas tarefas relativas a provas e demonstrações envolvendo o conteúdo "quadriláteros", nos livros selecionados.

Apoiando-nos na Teoria Antropológica do Didático, analisamos os livros escolhidos em termos de tarefa, técnica e bloco teórico-tecnológico, investigando como os autores apresentam o método dedutivo e seus termos próprios e como é feito o estudo dos quadriláteros, tendo como foco as definições e as demonstrações.

A teoria antropológica do didático, desenvolvida por Yves Chevallard a partir dos anos 1990, tem como objeto de estudo o homem frente às situações matemáticas. Chevallard (1999) afirma que toda atividade humana pode ser descrita a partir de um modelo único, o qual chamou de praxeologia, ou organização praxeológica. Ainda afirma que todo problema solicita meios para resolvê-lo e o processo que dá suporte teórico a essa resolução é, no contexto da matemática, a organização praxeológica matemática, ou organização matemática. Chevallard (1999) dá a esse problema matemático o nome de tarefa. Para uma dada tarefa existe uma técnica (que é o modo de realizar a tarefa), uma tecnologia que justifica a técnica e uma teoria que fundamenta a tecnologia. Esses elementos compõem dois blocos: um bloco técnico prático, composto de tarefa e técnica, e um bloco tecnológico-teórico, composto de tecnologia e teoria. É o bloco tecnológico teórico que permite a compreensão de uma técnica e até a possibilidade de uma nova técnica para resolver uma dada tarefa.

Chevallard (1999) introduziu também o construto "Organização Didática", que podemos caracterizar como sendo, por exemplo, uma situação em que um professor $A$, de uma instituição $I$ (uma escola) apresenta a um aluno $C$ um objeto $O$. Para apresentar esse objeto ao aluno, é necessário que o professor organize uma situação que favoreça o relacionamento entre o aluno e o objeto, isto é, uma situação que permita ao sujeito adquirir saberes sobre o objeto.

Uma tarefa é uma atividade específica que pertence a um tipo de tarefa, que por sua vez pertence a um gênero de tarefa. Uma tarefa e o tipo de tarefa que lhe corresponde são geralmente designados por um verbo: 'resolver', 'fazer' e 'demonstrar' dizem respeito a 
gêneros de tarefas, enquanto 'resolver um problema', 'fazer um bolo' e 'demonstrar um teorema' são os tipos de tarefas correspondentes. Um gênero de tarefa solicita uma particularidade para que seu sentido se complete; essa particularidade é o tipo de tarefa. Se $T$ é um tipo de tarefa associado a um gênero de tarefa $t$, Chevallard (1999) diz que $T \in t$, exemplo: 'demonstrar que os lados opostos de um paralelogramo são congruentes' é uma tarefa enquanto 'demonstrar propriedade do paralelogramo' é um tipo de tarefa correspondente. 'Demonstrar', por sua vez, é um gênero de tarefa.

Um tipo de tarefa solicita uma execução, isto é, determinado tipo de tarefa requer uma forma pela qual ela possa ser desenvolvida, forma essa que Chevallard (1999) chama de técnica. Assim, uma técnica é uma maneira de fazer uma tarefa. Uma tarefa $T$ solicita uma técnica $\tau$, que é a maneira de executar $T$. O par $[T / \tau]$ é chamado, na teoria antropológica do didático, de bloco prático-técnico, que corresponde ao saber fazer.

Nesta pesquisa, analisamos as organizações matemáticas e didáticas presentes em três livros de geometria indicados nas referências de cursos de licenciatura em matemática, e a relação entre o objeto matemático $(O)$ 'quadrilátero', as pessoas $(A)$ 'autores' e a instituição $(I)$ 'livro' em termos de tarefas, técnicas e bloco teórico-tecnológico. Por meio de uma organização didática, identificamos a organização matemática referente a ‘quadrilátero' a partir das tarefas propostas pelos autores e da análise das técnicas e do bloco teórico-tecnológico relativos a cada tarefa.

Neste trabalho, usaremos também a distinção entre explicação, prova e demonstração de Balacheff (2000). De acordo com este autor (apud, FERREIRA, 2016, p 43)

\begin{abstract}
Explicação: Um discurso que visa tornar inteligível o caráter de verdade, adquirido pelo locutor, de uma proposição ou de um resultado, os quais podem ser discutidos, refutados ou aceitos; Prova: Uma explicação aceita por dada comunidade em dado momento. Essa decisão pode ser objeto de um debate voltado a determinar um sistema de validação comum aos interlocutores; Demonstração: Um tipo de prova dominante em matemática, com uma forma particular. Trata-se de uma série de enunciados que se organizam segundo um conjunto bem definido de regras.
\end{abstract}

Balacheff (2004, apud FERREIRA, 2016, p.44) afirma que

a falta de esclarecimento pode provocar equívocos na comunicação da pesquisa. Além disso, e principalmente, acreditamos que fazer uma distinção entre os termos 'explicação', 'prova' e 'demonstração' é condição necessária para que estas sejam praticadas em todos os níveis de ensino.

A distinção demonstração e prova implica aceitar outras produções de alunos para estabelecer a validade de uma afirmação. No entanto, o fato de aceitar outras formas de provas produzidas pelos alunos não minimiza a importância do papel da demonstração para o ensino da 
matemática. Balacheff (2010, p.115, apud FERREIRA, 2016, p.45) corrobora esse fato e considera que não se pode aprender matemática sem aprender demonstração:

[...] a prova matemática tem características específicas, entre elas um tipo formal de texto [...], uma organização específica e uma robustez indiscutível uma vez sintaticamente corretas. Essas características deram à matemática a reputação de ter práticas excepcionalmente rigorosas em relação a outras disciplinas, práticas que não são socialmente determinadas, mas inerentes à natureza da própria matemática.

Essa importância atribuída à prova e demonstração também no âmbito da educação matemática faz com que alguns pesquisadores, como Balacheff, defendam que as provas possam ser trabalhadas desde as primeiras séries.

A Teoria dos Registros de Representação Semiótica (TRRS) de Duval (2009). Para este autor, as representações semióticas se referem a um sistema específico de signos, que, no âmbito da matemática, incluem a língua natural, a escrita algébrica, os gráficos cartesianos e as figuras geométricas. Duval (2011) assevera que, mais que tornar possível o acesso aos objetos, temos a possibilidade de transformar uma representação em outra representação semiótica. Essas transformações podem ocorrer dentro de um mesmo sistema (o tratamento) ou entre sistemas semióticos diferentes (a conversão).) Essas transformações "constituem a dinâmica cognitiva de toda atividade matemática" (DUVAL 2011, p. 69) e que nem todo sistema semiótico é suficiente para efetuar essas transformações.

A geometria faz apelo às seguintes representações: a língua natural, a simbólica e a representações geométricas ou figurais. Para serem resolvidos, os problemas de geometria necessitam, em sua maioria, do apoio da figura, o que corresponde à conversão de um problema em língua natural para um problema no registro figural.

Neste texto, inicialmente, justificamos a escolha do objeto matemático que será explorado e a dos livros que serão analisados, definimos os critérios de escolha dos livros, em seguida apresentamos nossa análise dos livros selecionados e, finalmente, tecemos nossas considerações sobre a análise dos livros didáticos.

\section{Nosso objeto matemático: o quadrilátero}

Nossa pesquisa está relacionada às dificuldades apresentadas por alunos de licenciatura em matemática ao lidarem com demonstrações geométricas. Para cumprir nosso objetivo, foi necessário eleger um conteúdo geométrico por intermédio do qual pudéssemos abordar o tema pesquisado, fazer nossas análises e obter respostas para nossas indagações.

Buscamos um conteúdo em que pudéssemos abordar de forma reflexiva as características de uma definição e as consequências da interpretação de um conceito, e que também propiciasse 
a introdução do método dedutivo. Desse modo, elegemos o conteúdo "quadriláteros" por entendermos que este propicia um campo fértil para atingirmos nossos objetivos. Além disso, as relações entre as propriedades dos quadriláteros permitem trabalhar as demonstrações e abordar diversos conteúdos da geometria plana, tais como a congruência de triângulos.

A definição de quadrilátero é apresentada na educação básica nas primeiras séries do ensino fundamental, no sexto ano é desenvolvida sua sistematização, no oitavo, propõe-se a demonstrações das propriedades dos quadriláteros. Espera-se que no ensino médio os alunos já dominem este tópico. No entanto, a literatura nos mostra, a análise do questionário e a nossa experiência confirmam, que os alunos de licenciatura em matemática apresentam problemas conceituais relativos a quadriláteros, dificuldades em sua identificação e no estabelecimento de relações entre os quadriláteros notáveis.

Compreendendo a importância da definição para o desenvolvimento do pensamento geométrico, acreditamos que é imprescindível que em nossa sequência sejam contempladas tarefas relacionadas às definições dos quadriláteros.

Diante dos argumentos apresentados, cabe aqui abrirmos espaço para apresentarmos diferentes definições de quadriláteros notáveis, propostas ao longo da história por alguns matemáticos, e as variações que a definição de trapézio e trapézio isósceles pode adquirir. Nossa exposição se baseará em dois artigos de Vicenzo Bongiovanni (BONGIOVANNI, 2004; 2010).

No primeiro, Bongiovanni (2004) apresenta quatro definições distintas para quadriláteros notáveis, as quais admitem relações distintas entre si, dependendo da classificação adotada. As classificações apresentadas pelo autor provêm de Euclides, Legendre e Hadamard.

No livro I de Os elementos, Euclides define "figura quadrilátera" como sendo aquela "contida por quatro linhas retas", e assim define os quadriláteros notáveis: Quadrado: figura quadrilátera de quatro lados iguais com ângulos retos; Oblongo (retângulo): figura quadrilátera com ângulos retos, mas que não tem quatro lados iguais; Rombo (losango): figura quadrilátera com quatro lados iguais, mas não com ângulos retos; Romboide (paralelogramo): figura quadrilátera que tem lados e ângulos opostos iguais entre si, mas não tem quatro lados iguais nem ângulos retos. Na definição de Euclides, o conjunto formado por cada classe de quadrilátero notável é disjunto. Segundo Bongiovanni (2004), a classificação de Legendre é mais rigorosa e menos intuitiva que a de Euclides. 
Legendre caracteriza os quadriláteros da seguinte forma: O quadrado tem lados iguais e ângulos retos; O retângulo tem ângulos retos sem ter os lados iguais; O losango tem lados iguais sem que os ângulos sejam retos; O paralelogramo tem lados opostos paralelos.

Pela definição de Legendre, o quadrado não é um retângulo e não é um losango, porém todos eles são paralelogramos. Também podemos observar que os quadriláteros que Euclides chama de oblongo, rombo e romboide passaram a se denominar respectivamente retângulo, losango e paralelogramo.

Segundo Bongiovanni (2004), Hadamard caracterizou os quadriláteros notáveis de maneira mais ampla: Quadrado é um quadrilátero que tem todos os lados iguais e todos os ângulos iguais; Retângulo é um quadrilátero que tem todos os ângulos iguais e, consequentemente, retos; Losango é um quadrilátero que tem os quatro lados iguais; Paralelogramo é um quadrilátero que tem os quatro lados paralelos dois a dois.

De acordo com a definição de Hadamard, um quadrado também é retângulo e losango, ao passo que o quadrado, o retângulo e o losango são todos paralelogramos. A caracterização de Hadamard (Figura 1) é a que hoje consta nos livros didáticos.

Figura 1: Relações ente os quadriláteros, segundo Hadamard

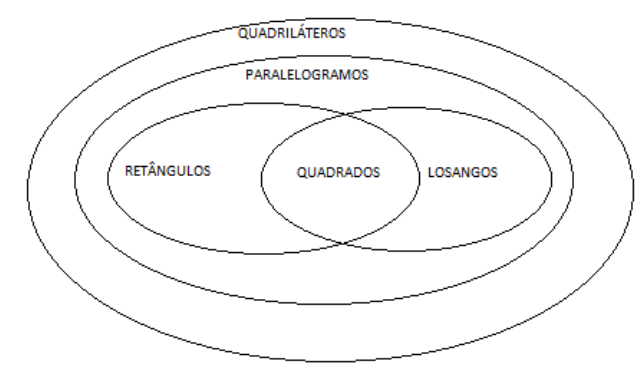

Fonte: Ferreira (2016, p.105)

Quanto à definição de trapézio, esta causa dúvida até entre professores. Duas definições são consideradas: Trapézio é um quadrilátero em que dois lados opostos são paralelos; Trapézio é um quadrilátero em que exatamente dois lados opostos são paralelos.

Segundo a primeira definição, o paralelogramo é um trapézio, o que pode causar dúvidas em alunos e professores (MAIOLI, 2001; SILVA, 2007) pela ênfase dada à representação figural e não às propriedades do objeto. De modo geral, as representações de trapézio que os livros didáticos trazem são variações das que constam na Figura 2. 
Figura 2: Representações de trapézios habitualmente encontradas em livros didáticos.

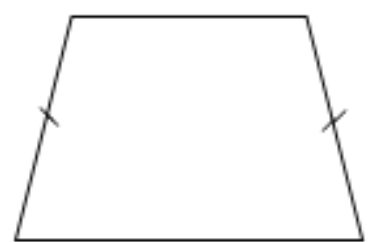

(1)

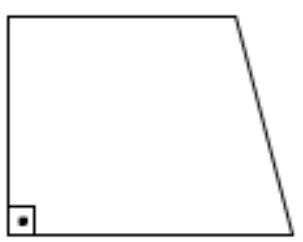

(2)

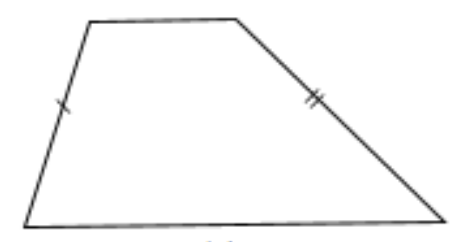

(3)

Fonte: Ferreira (2016, p.105).

A depender da definição de trapézio adotada, é necessário haver coerência com as demais definições adotadas e propriedades enunciadas. Um caso que pode gerar incoerência é a definição de trapézio isósceles e de suas propriedades. Ao definir este tipo de trapézio como sendo aquele que apresenta dois lados congruentes, não podemos assumir que os ângulos de suas bases e suas diagonais sejam congruentes, uma vez que o paralelogramo seria um trapézio isósceles que não satisfaz tais propriedades. Bongiovanni (2010, p. 10) propõe uma definição de trapézio isósceles que seria coerente com as propriedades que já estão incorporadas por alunos e professores: "Trapézio isósceles é um trapézio que tem um único par de lados opostos congruentes". Ao assumir esta definição, excluímos os paralelogramos da lista dos trapézios isósceles.

Nos trabalhos de Maioli (2001) e Silva (2007), o objeto matemático ‘quadrilátero’ permitiu a abordagem de diferentes tipos de provas, uma vez que proporcionou condições para propor conjecturas e enunciar e demonstrar teoremas, revelando-se assim um conteúdo rico para a introdução do método dedutivo. Também as caracterizações dos quadriláteros notáveis discutidas por Bongiovanni (2010) mostram como esse conteúdo permite trabalhar as implicações de uma interpretação equivocada de uma definição.

Diante dessas constatações, observamos que, do ponto de vista matemático, o conteúdo "quadriláteros" permite explorar um número significativo de propriedades geométricas que possibilitam a resolução de diversos problemas. Viabiliza também a resolução de problemas com o uso de régua e compasso, focando o levantamento de conjecturas e favorece a exploração de teoremas, teoremas recíprocos, demonstrações e diferentes registros de representação.

Diante do que foi abordado neste tópico, observamos a relevância de analisar livros de geometria utilizados em cursos de licenciatura em Matemática para evidenciar como autores desses livros lidam com atividades que envolvam as definições de quadriláteros, uma vez que elas influenciam na sua classificação, enfatizando a importância de se manter coerente com a definição escolhida. 


\section{Critérios de escolha dos livros de geometria plana indicados nos cursos de licenciatura em matemática}

Para nortear nossa investigação, levantamos algumas questões: De que forma os livros de geometria plana, utilizados nos cursos de licenciatura em matemática, estão abordando as demonstrações relativamente ao tópico 'quadriláteros'? As tarefas propostas nos livros de geometria plana, utilizados nos cursos de licenciatura, têm potencial para motivar os alunos a fazer descobertas e propiciar a estes vivenciar momentos de ação, formulação e validação? As tarefas propostas nos livros de geometria plana, utilizados nos cursos de licenciatura, têm potencial para induzir os alunos a pensar sobre a figura, fazer conversões entre representações de diferentes registros e evoluir da apreensão perceptiva para a discursiva?

Para cobrir todas as regiões brasileiras nesse levantamento, consultamos os projetos pedagógicos disponíveis nos sítios de 21 universidades. Dos 20 programas analisados, constatamos que três obras receberam números expressivos de indicações:

- BARBOSA, J.L.M. Geometria euclidiana plana. 8 ed. Rio de Janeiro: IMPA, 2006. (14 indicações; doravante designado LG1.)

- DOLCE, O.; POMPEO, J.N. Fundamentos de matemática elementar: geometria plana. 7 ed. São Paulo: Atual, 2009. v. 9. (12 indicações; doravante designado LG2.)

- REZENDE, E.Q.; QUEIROZ, M.L.B. Geometria euclidiana plana e construções geométricas. Campinas: Unicamp, 2008. (10 indicações; doravante designado LG3.)

A frequência das indicações e o fato de serem obras especificamente voltadas à geometria plana nos levaram a escolhê-las para análise.

\section{Análise dos livros selecionados}

Iniciaremos este tópico identificando o público ao qual, segundo seus autores, os livros selecionados se destinam.

Barbosa (2006) propõe-se a fazer uma apresentação axiomática da geometria e indica seu livro (LG1) para alunos de licenciatura em matemática, explicando que seu objetivo é dar ao futuro professor uma visão mais ampla daquilo que irá futuramente ensinar. $\mathrm{O}$ autor esclarece não estar propondo que o futuro professor adote o mesmo tipo de apresentação quando estiver lecionando na educação básica.

Dolce e Pompeo (2009) expõem que seu livro (LG2) se destina a alunos do ensino médio, visando prepará-los para exames vestibulares, ou a universitários, a título de revisão dos conteúdos do ensino médio.

Rezende e Queiroz (2008) indicam seu livro (LG3) a alunos e professores em cursos de especialização e graduação em matemática ou áreas afins, bem como a professores de 
matemática de outros níveis de ensino. Acrescentam que esperam proporcionar ao leitor maior facilidade em organizar raciocínios e construir argumentações lógicas.

Note-se que apenas um autor indica sua obra especialmente para alunos de licenciatura em matemática.

O livro LG1 é estruturado em 11 capítulos e o conteúdo 'quadriláteros' é abordado no Capítulo 6, intitulado "O axioma das paralelas". Ao final de cada capítulo é proposta uma série de exercícios e de problemas, seguidos de um texto que o autor chama de "Comentário". O final do livro traz uma seção de exercícios intitulada "Revisão e aprofundamento".

O livro LG2 é estruturado em 19 capítulos e o conteúdo 'quadriláteros' é abordado no capítulo VII, intitulado "Quadriláteros notáveis". O volume traz quatro textos históricos de autoria do professor Hygino Domingues em seções denominadas "Leitura", localizadas após os capítulos IV, VIII, XII e XVI. Os textos focalizam os seguintes temas: Euclides e a geometria dedutiva; Papus: o epílogo da geometria grega; Legendre: por uma geometria rigorosa e didática; Hilbert e a formalização da geometria.

Ao final de cada conteúdo é apresentada uma série de exercícios, alguns dos quais são resolvidos pelos autores. No final do livro, é disponibilizada uma lista de testes de vestibular, organizada por conteúdo. O autor não explicita detalhadamente a estrutura de cada volume.

O livro LG3 é estruturado em 14 capítulos, sendo que sete abordam os conteúdos de geometria plana euclidiana e os demais se destinam às construções geométricas. O conteúdo 'quadriláteros' é apresentado no capítulo 4, intitulado "O postulado das paralelas e a geometria euclidiana". Ao final de cada capítulo é apresentada uma seção denominada "Nota histórica", seguida de uma série de exercícios propostos.

\subsection{Análise das organizações matemáticas e didáticas dos livros selecionados}

À luz da teoria antropológica do didático, analisamos esses livros em termos de tarefa, técnica e bloco teórico-tecnológico, investigando como os autores apresentam o método dedutivo e seus termos próprios e como é feito o estudo dos quadriláteros, tendo como foco as definições e as demonstrações.

Formulamos cinco questões que darão origem às tarefas com suas respectivas técnicas, que por sua vez serão justificadas por um bloco teórico-tecnológico.

Devido à limitação do espaço, focalizaremos nossa análise nas tarefas voltadas ao professor. Neste tópico utilizaremos as seguintes notações relacionadas à praxeologia:

- $\quad \mathrm{Q}_{\mathrm{i}}$ : questão $i$; 
- $\mathrm{T}_{\mathrm{i}} \mathrm{Q}_{\mathrm{j}}$ : tarefa $i$ referente à questão $j$;

- $\quad t_{\mathrm{k}}\left(\mathrm{T}_{\mathrm{i}} \mathrm{Q}_{\mathrm{j}}\right)$ : técnica $k$, referente à tarefa $i$ da questão $j$;

- $\quad[\theta / \Theta]_{\mathrm{i}}$ : discurso tecnológico-teórico referente à questão $i$.

Nas justificativas matemáticas apresentadas neste e nos próximos tópicos, utilizaremos as notações $\overline{A B}$, para representar o segmento de reta de extremos $A$ e $B ; A B$, para representar a medida do segmento $\overline{A B} ; \overrightarrow{A B}$, para representar a semirreta de origem $A$ e que contém o ponto $B$; $A \hat{O} B$, para representar o ângulo de vértice $O$ e lados $\overrightarrow{O A}$ e $\overrightarrow{O B}$; e $\operatorname{med}(A \hat{O} B)$, para representar a medida desse ângulo. Quando não houver risco de confusão, representaremos o ângulo $A \hat{O} B$ simplificadamente por $\hat{O}$.

Começamos nossa análise pelas praxeologias relacionadas à questão 1 a seguir.

\section{Questão $1\left(Q_{1}\right)$ : Como o autor aborda o método dedutivo e seus termos próprios?}

Quadro 1: Tarefas e técnicas relacionadas à Q1

\begin{tabular}{|l|l|}
\hline Tarefas relacionadas à questão Q1 & Técnica que cumprem essas tarefas \\
\hline $\begin{array}{l}\mathbf{T}_{1} \mathbf{Q}_{1}: \text { Explicar o que vem a ser o método } \\
\text { dedutivo. }\end{array}$ & $\begin{array}{l}t_{1}\left(\mathrm{~T}_{1} \mathrm{Q}_{1}\right) \text { : abordagem histórica. } \\
t_{2}\left(\mathrm{~T}_{1} \mathrm{Q}_{1}\right) \text { : abordagem direta, sem utilizar a história }\end{array}$ \\
\hline $\begin{array}{l}\mathbf{T}_{2} \mathbf{Q}_{1}: \text { Explicar o significado das seguintes } \\
t_{1}\left(\mathrm{~T}_{2} \mathrm{Q}_{1}\right) \text { : Levantamento sobre a diferenciação das } \\
\text { noções: postulado, axioma, teorema, prova, } \\
\text { noções de postulado, axioma, teorema, prova, } \\
\text { demononstração, hipótese, tese e recíproca. }\end{array}$ \\
\hline $\begin{array}{l}\mathbf{T}_{3} \mathbf{Q}_{1}: \text { Identificar se há utilização das seguintes } \\
\text { noções: postulado, axioma, teorema, prova, } \\
\text { demonstração, hipótese, tese, recíproca }\end{array}$ & $\begin{array}{l}t_{1}\left(\mathrm{~T}_{3} \mathrm{Q}_{1}\right) \text { : Levantamento sobre a utilização das } \\
\text { noços de postulado, axioma, teorema, prova, } \\
\text { demonstração, hipótese, tese e recíproca }\end{array}$ \\
\hline
\end{tabular}

Fonte: Construção nossa

$[\theta / \Theta]_{1}$ : O discurso teórico-tecnológico associado às tarefas $\mathbf{T}_{\mathbf{1}} \mathbf{Q}_{\mathbf{1}}, \mathbf{T}_{\mathbf{2}} \mathbf{Q}_{\mathbf{1}}$ e $\mathbf{T}_{\mathbf{3}} \mathbf{Q}_{\mathbf{1}}$ é o texto histórico ou direto informando o que vem a ser o método dedutivo, esclarecendo quanto aos termos próprios desse método e como estes são utilizados.

No Quadro 1, apresentamos uma síntese das tarefas referentes a Q1 realizadas pelos autores de LG1, LG2 e LG3. O símbolo $\checkmark$ indica que os autores realizaram a tarefa ao menos parcialmente.

Quadro 2: Síntese das tarefas realizadas pelos autores dos livros analisados, referentes à questão 1

\begin{tabular}{|c|c|c|c|c|}
\cline { 3 - 4 } \multicolumn{2}{c|}{} & LG1 & LG2 & LG3 \\
\hline & $t_{1}\left(\mathrm{~T}_{1} \mathrm{Q}_{1}\right)$ & & & $\checkmark$ \\
\hline $\mathrm{T}_{1}$ & $t_{2}\left(\mathrm{~T}_{1} \mathrm{Q}_{1}\right)$ & & & $\checkmark$ \\
\hline $\mathrm{T}_{2}$ & $t_{1}\left(\mathrm{~T}_{2} \mathrm{Q}_{1}\right)$ & $\checkmark$ & $\checkmark$ & $\checkmark$ \\
\hline $\mathrm{T}_{3}$ & $t_{1}\left(\mathrm{~T}_{3} \mathrm{Q}_{1}\right)$ & $\checkmark$ & $\checkmark$ & \\
\hline
\end{tabular}

Fonte: Ferreira (2016, p. 110).

Em LG1, o autor inicia o estudo de geometria referindo-se a 'ponto', 'reta' e 'plano' como 'figuras geométricas elementares'. Utiliza os termos 'axioma', 'postulado', 'teorema', 
'corolário', 'definição', 'demonstração' e 'prova', bem como as expressões 'necessário e suficiente' e 'se, e só se', e, a princípio, não faz nenhum esclarecimento quanto ao método dedutivo ou seus elementos.

No final do capítulo 1, no primeiro comentário, o autor explica o que vem a ser 'método dedutivo', comparando-o a um jogo em que as peças são as figuras geométricas elementares e as regras são os axiomas. Associa a determinação das propriedades das figuras geométricas, a que chama de 'teorema' ou 'proposição', ao objetivo final do jogo.

O autor não utiliza texto histórico ou texto direto para esclarecer o que vem a ser o método dedutivo, mas faz uma comparação com um jogo e suas regras. Desse modo, a tarefa foi realizada com a utilização de uma técnica diferente das que foram propostas em $t_{1}\left(\mathrm{~T}_{1} \mathrm{Q}_{1}\right) \mathrm{e}$ $t_{2}\left(\mathrm{~T}_{1} \mathrm{Q}_{1}\right)$

O comentário mencionado também informa que os teoremas ou proposições "devem ser deduzidos por meio de raciocínio lógico a partir dos axiomas fixados ou a partir de outras propriedades já estabelecidas" (LG1, p. 12). No entanto, o autor não deixa claro que essa dedução "por meio de raciocínios lógicos” é o que ele associa ao termo 'prova' utilizado ao demonstrar os teoremas. O autor faz uso do registro figural, enfatizando que a figura está sendo usada apenas como "um instrumento de ajuda à nossa intuição e linguagem” (LG1, p. 2).

Os autores de LG2, por sua vez, introduzem a geometria estabelecendo uma distinção entre noção primitiva e outros entes geométricos, que são apresentados mediante definições. Tenta esclarecer os significados de 'postulado', ou 'axioma', chamando-os de propriedades primitivas que são aceitas sem demonstração, e de 'proposição', como sendo uma propriedade aceita mediante demonstração. Não esclarece, porém, o significado do termo 'demonstração' ou o que vem a ser o método dedutivo, embora faça referência a este na leitura "Euclides e o método dedutivo" (Figura 3).

Figura 3: Trecho da leitura "Euclides e a geometria dedutiva"

Mas, sem dúvida, o forte dos Elementos é a geometria. A partir de cinco noções comuns, cinco postulados específicos e algumas definições, centenas de teoremas (467 em toda a obra) são deduzidos, alguns de grande profundidade. Além de ser o mais antigo texto de matemática na forma axiomático-dedutiva a chegar a nossos dias, nele Euclides foi muito feliz na escolha e no enunciado de seus postulados básicos. E soube usá-los com proficiência. Assim, não é sem motivo que os Elementos, por dois milênios, além de texto fundamental de geometria, foi o modelo de boa matemática.

Fonte: LG2, p. 60. 
São utilizados em LG2 os termos 'definição', 'postulado', 'teorema' e 'demonstração', mas alguns resultados são enunciados e demonstrados sem que os termos 'proposição', 'teorema' ou 'demonstração' sejam explicitados.

Figura 4: Demonstração da existência de retas concorrentes

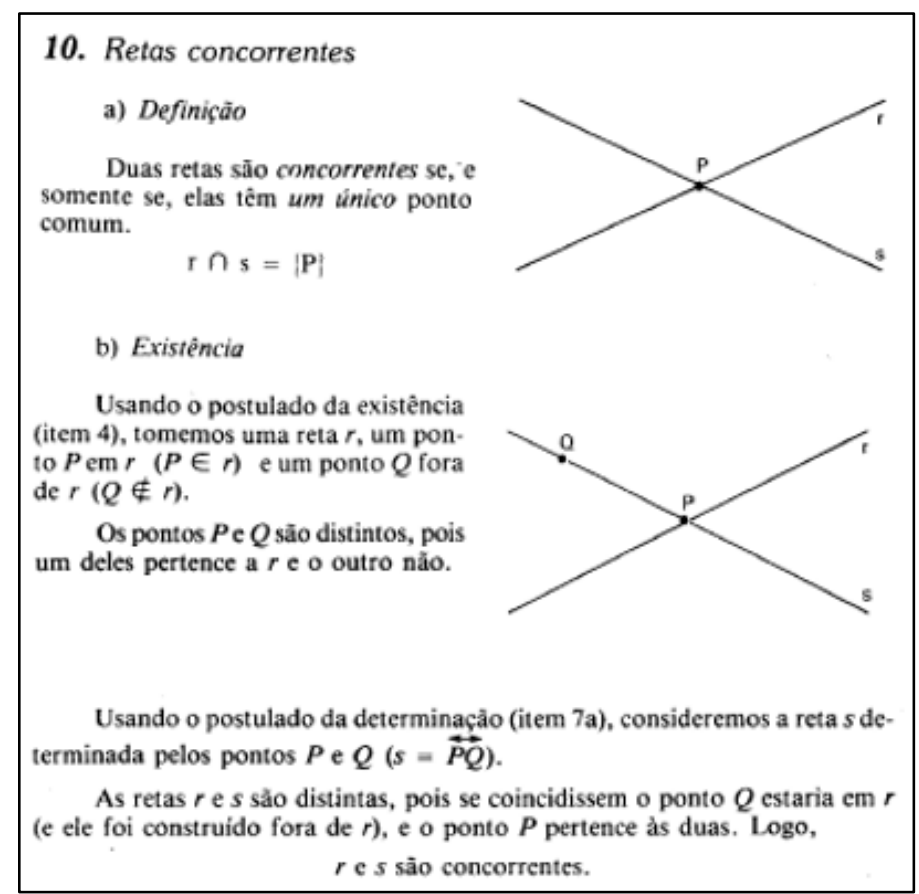

Fonte: LG2, p. 4-5.

A Figura 4, que reproduz trecho desse livro, mostra como é feita a demonstração da existência de retas concorrentes sem que as palavras 'prova' ou 'demonstração' sejam explicitadas.

Em LG2 o termo 'teorema' é utilizado apenas para resultados considerados importantes para os autores, como teorema do triângulo isósceles, teorema de Pitágoras, teorema de Tales e outros. Os demais resultados são enunciados e demonstrados sem fazer referência aos termos 'teorema' ou 'demonstração', como exemplificado na Figura 4. Essa prática explica o fato de muitos alunos só considerarem como teoremas os que vêm acompanhados de um nome contendo esse termo.

Em LG2 não são enunciados teoremas utilizando a expressão 'se, e somente se'. Os teoremas recíprocos são enunciados separadamente na forma 'se, então' e, na demonstração, os autores destaca 'hipótese' e 'tese'. Somente após a demonstração esclarecem que, neste caso, a condição é necessária e suficiente. A Figura 5 exemplifica a forma como os teoremas recíprocos são abordados. (A demonstração completa do teorema encontra-se nas páginas 157 e 158 da obra.) 
Figura 5: Propriedade dos quadriláteros circunscritíveis.

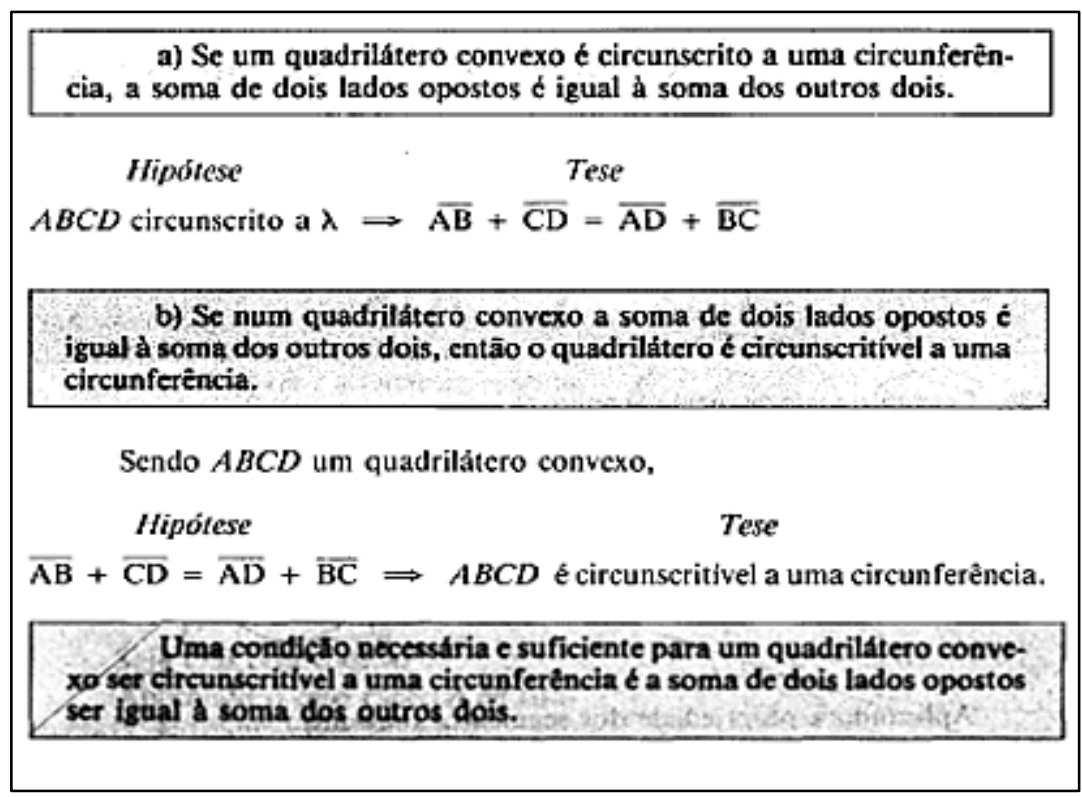

Fonte: LG2 (p. 157-158)

Em LG3, a geometria é introduzida com 'ponto', 'reta' e 'plano' como termos indefinidos. Na apresentação, as autoras explicam o que vêm a ser 'método dedutivo' e 'postulado', ou 'axioma'. No entanto, utilizam sem explicação o termo 'demonstração' para esclarecer o significado do método dedutivo.

São utilizados os termos 'postulado', ‘definição', 'teorema', 'lema', 'corolário' e 'demonstração', mas não são oferecidas explicações desses termos.

Os três livros têm estruturas semelhantes. Embora LG2 seja o único voltado ao ensino médio, não traz explicação sobre o método dedutivo, embora dele faça uso. LG1 e LG3 trazem alguma noção sobre esse método, o que pode motivar o leitor buscar aprofundamento.

Apenas LG1 tenta esclarecer o significado do termo 'demonstração', mas utiliza o termo 'prova' ao demonstrar as propriedades enunciadas. Embora os empregue como sinônimos ao afirmar que os teoremas são "deduzidos através da demonstração", seria coerente utilizar este termo último ao demonstrar as propriedades enunciadas.

As provas utilizadas nos três livros são do tipo conceitual, o que era previsível em LG1 e LG3, uma vez que seus conteúdos se destinam para o ensino superior.

Quanto aos registros de representação, nos três livros são figurais, discursivos e simbólicos, mas LG2 é o único a utilizá-los simultaneamente, em todas as definições, postulados e propriedades. Já LG1 e LG3 privilegiam os registros em língua natural e simbólicos. Para Duval (2011), a simultaneidade de registros figurais e em língua natural é fundamental para potencializar a aprendizagem. 
Nenhum dos três livros explorou o estudo das condições necessárias e suficientes. Jahnke (2008) afirma que a distinção entre condições necessárias e suficientes não é óbvia para os alunos, mesmo universitários. Considera ainda que um número reduzido de exemplos não é suficiente para ultrapassar essas dificuldades, uma vez que elas se encontram enraizadas.

Outro aspecto que merece destaque é a axiomática que os livros utilizam para explorar medidas de segmentos. Em LG1, considera-se a noção 'estar entre' como primitiva, assim como Hilbert, mas usam-se números reais para formalizar a noção de medidas de segmentos, tomando como referência a obra de Pogorélov. LG3 segue os postulados de Birkhoff, considerando a noção de 'medida' como primitiva e definindo a noção 'estar entre', que utiliza a correspondência entre números reais e pontos de uma reta. LG2 adota a axiomática de Hilbert. Considera a noção 'estar entre' e 'congruência' como primitivas e utiliza o postulado do transporte de segmento para introduzir o conceito de medida de segmento.

Uma vez que estes três livros são indicados simultaneamente em um grande número de universidades, esse esclarecimento deve ser feito pelo professor, já que os conceitos envolvidos podem gerar confusão no aluno. $\mathrm{O}$ exemplo apresentado acima presta-se também a abrir uma discussão sobre as implicações da escolha de axiomáticas distintas.

Questão $2\left(Q_{2}\right)$ : Como são introduzidos o conceito de quadriláteros e a soma de seus ângulos internos?

Quadro 3: Tarefas e técnicas relacionadas com $\mathrm{Q}_{2}$

\begin{tabular}{|c|c|}
\hline Tarefas relacionadas à questão Q2 & Técnicas que cumprem essas tarefas \\
\hline $\begin{array}{l}\mathrm{T}_{1} \mathrm{Q}_{2} \text { : Apresentar a definição de quadrilátero e } \\
\text { seus elementos }\end{array}$ & $\begin{array}{l}t_{1}\left(\mathrm{~T}_{1} \mathrm{Q}_{2}\right) \text { : Utilizar o registro de representação em } \\
\text { língua natural. } \\
t_{2}\left(\mathrm{~T}_{1} \mathrm{Q}_{2}\right) \text { : Utilizar o registro de representação } \\
\text { simbólico. } \\
t_{3}\left(\mathrm{~T}_{1} \mathrm{Q}_{2}\right) \text { : Utilizar o registro de representação } \\
\text { figural. }\end{array}$ \\
\hline $\begin{array}{l}T_{2} Q_{2} \text { : Apresentar a soma dos ângulos internos } \\
\text { de um quadrilátero. }\end{array}$ & $\begin{array}{l}t_{1}\left(\mathrm{~T}_{2} \mathrm{Q}_{2}\right): \text { Utilizar a triangulação do quadrilátero. } \\
t_{2}\left(\mathrm{~T}_{2} \mathrm{Q}_{2}\right) \text { : Enunciar a propriedade sem } \\
\text { demonstração }\end{array}$ \\
\hline
\end{tabular}

Fonte: Construção nossa

$[\theta / \Theta]_{2}$ : O discurso teórico-tecnológico associado às tarefas $T_{1} Q_{2}$ e $T_{2} Q_{2}$ é a definição de quadrilátero, a triangulação do quadrilátero (divisão do quadrilátero em dois triângulos por meio de uma de suas diagonais), a soma dos ângulos internos de um triângulo e a soma dos ângulos internos de um quadrilátero.

As técnicas $t_{1}\left(\mathrm{~T}_{1} \mathrm{Q}_{2}\right), t_{2}\left(\mathrm{~T}_{1} \mathrm{Q}_{2}\right)$ e $t_{3}\left(\mathrm{~T}_{1} \mathrm{Q}_{2}\right)$ só se distinguem pelo tipo de registro utilizado. Para um aprendizado significativo, segundo Duval (2009a, b), devem-se mobilizar simultaneamente ao menos dois registros de representação. 
Com relação à segunda tarefa, como LG1 e LG3 são voltados ao ensino superior, acreditamos que ambos utilizem a técnica $t_{1}\left(\mathrm{~T}_{2} \mathrm{Q}_{2}\right)$ que consiste em traçar a diagonal que parte de um de seus vértices, dividindo o quadrilátero em dois triângulos, e utilizar o fato de que a soma dos ângulos internos de um triângulo é $180^{\circ}$. Por ser um resultado considerado elementar, é provável também a utilização da técnica $t_{2}\left(\mathrm{~T}_{2} \mathrm{Q}_{2}\right)$ que consiste em apenas enunciar a propriedade. O Quadro 2 sumariza a análise da questão 2.

Quadro 4: Análise da questão 2 (Q2).

\begin{tabular}{|c|c|c|c|c|}
\cline { 3 - 5 } \multicolumn{2}{c|}{} & LG1 & LG2 & LG3 \\
\hline \multirow{3}{*}{$T_{1}$} & $t_{1}\left(\mathrm{~T}_{1} \mathrm{Q}_{2}\right)$ & & $\checkmark$ & $\checkmark$ \\
\cline { 2 - 5 } & $t_{2}\left(\mathrm{~T}_{1} \mathrm{Q}_{2}\right)$ & & $\checkmark$ & $\checkmark$ \\
\cline { 2 - 5 } & $t_{3}\left(\mathrm{~T}_{1} \mathrm{Q}_{2}\right)$ & & $\checkmark$ & \\
\hline \multirow{2}{*}{$\mathrm{T}_{2}$} & $t_{1}\left(\mathrm{~T}_{2} \mathrm{Q}_{2}\right)$ & & & \\
\hline
\end{tabular}

Fonte: Ferreira (2016, p.115).

Dos três livros analisados, apenas LG1 não apresenta explicitamente a definição de quadrilátero. Na seção destinada aos exercícios do Capítulo 3 (“Axiomas sobre medição de ângulos"), é apresentada a definição de polígono (questão 30) e um quadro com os nomes dos polígonos (questão 35), incluindo o quadrilátero. Os demais livros explicitam a definição.

Maioli (2001) discute as implicações da má interpretação de uma definição e a importância de estudar suas características, o que nos estimulou a estudar as características de cada definição apresentada nos livros analisados, a fim de evitar interpretações equivocadas nas análises que se seguem.

Ao analisar como a definição é proposta em cada um dos livros, observamos que LG1 e LG3 utilizam a definição de polígono, uma vez que nessas duas obras esse conteúdo antecede o estudo dos quadriláteros. LG2, por sua vez, define quadrilátero utilizando a reunião de segmentos.

Visto que em LG1 a apresentação do objeto 'quadrilátero' é atrelada a outros polígonos, vamos analisar a definição de polígono considerada nesse volume. 
Figura 6: Definição de polígono apresentada em LG1

18. Uma poligonal é uma figura formada por uma seqüêneia de pontos $A_{1}, A_{2}, \ldots, A_{n}$ e pelos segmentos $A_{1} A_{2}, A_{2} A_{3}, A_{3} A_{4}$, $\ldots, A_{n-1} A_{n}$. Os pontos sio os vétices da poligonal e os segmentos sto os seus lados. Desenhe a poligonal $A B C D$ subendo que: $\overline{A B}=\overline{B C}=\overline{C D}=2 \mathrm{~cm}, A B C=120^{\circ} \mathrm{e}$ $B C D=100^{\circ}$.

19. Um poĺgono é uma poligonal em que as seguintes 3 condiçðes sĩo satisfeltas: (a) $A_{n}=A_{t}$, (b) os lados da poligonal se interceptam somente em suas extremidades, (c) cada vértice 6 extremidade de dols lados e (d) dois lados com mesma extremidade não pertencem a uma mesma reta. Das 4 figuras, abaixo, apenas duas são polfgonos. Determine quais são elas.
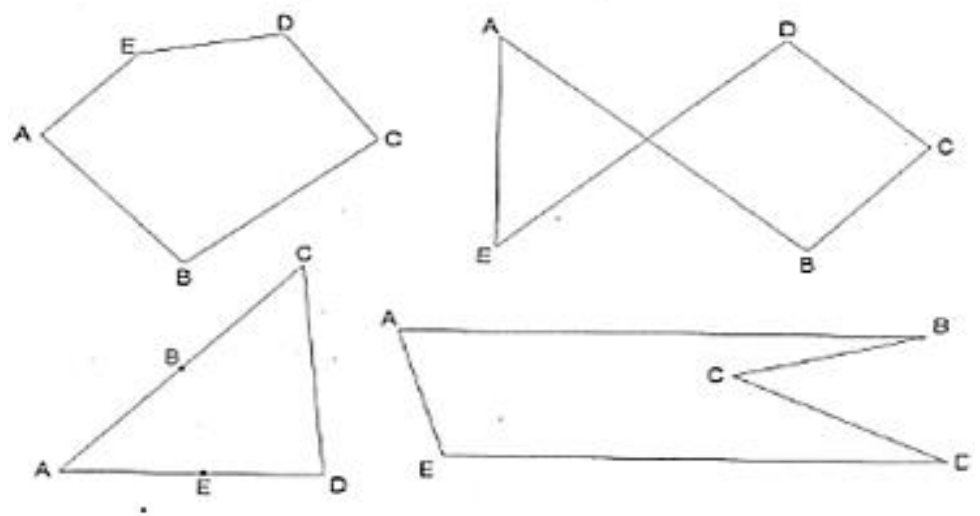

Um poligono de vértices $A_{1}, A_{2}, \ldots, A_{n+2}=A_{1}$, sená representado por $A_{1} A_{2} A_{3}, \ldots, A_{n}$. Ele tern $n$ lados, $n$ vértices e $n$ ângulos.

35. Polfgonos convexos recebem designaç̋̃es especiais. Sĩo as seguintes as designaçoes dadas a estes poligonos do acordo com set número de lados, até 10 lados.

\begin{tabular}{|c|c|}
\hline $\mathrm{n}^{2}$ de lados & nome do poligono convexo \\
\hline 3 & tríngulo \\
4 & quadrilítero \\
5 & pentígono \\
6 & hexágono \\
7 & heptágono \\
8 & octígono \\
9 & nonágono \\
10 & decégono \\
\hline
\end{tabular}

Dado um polfgono convexo mostre que qualquer de staas diagonals sempre o divide etn dois conjuntos convexos.

Fonte: LG1 (p. 38, 41, apud FERREIRA 2016, p.116).

Observamos na Figura 6 que em LG1 o polígono é definido como contorno, não sendo especificado que os pontos (vértices do polígono) foram tomados todos em um mesmo plano. Isso nos leva a concluir que o autor não excluiu a possibilidade de um polígono não plano. Poderíamos então considerar que a definição proposta pelo autor abrange quadriláteros não planos, mas, analisando o livro em sua íntegra, detectamos uma questão proposta em que se solicita ao aluno discutir a seguinte afirmação: "Todo polígono separa o plano em duas partes, uma limitada e outra ilimitada. (A parte limitada é referida como a região limitada pelo polígono, ou interior do polígono)" (LG1, p. 39). Embora o autor solicite a discussão da 
afirmação, faz-nos pensar que os polígonos definidos são planos. Seria, portanto, aconselhável deixar claro o tipo de polígono considerado.

Em LG3, a definição é apresentada no capítulo destinado a quadriláteros, mas, tal como em LG1, também está associada à definição de polígono: "Um quadrilátero é um polígono de quatro lados", sem deixar claro se o polígono é plano.

Em LG2, o estudo de quadrilátero antecede o de polígono e por isso a definição do primeiro não utiliza a do segundo, deixando, porém, claro que o quadrilátero é um contorno e é plano (Figura 7). Observamos também que o autor utiliza simultaneamente três registros de representação.

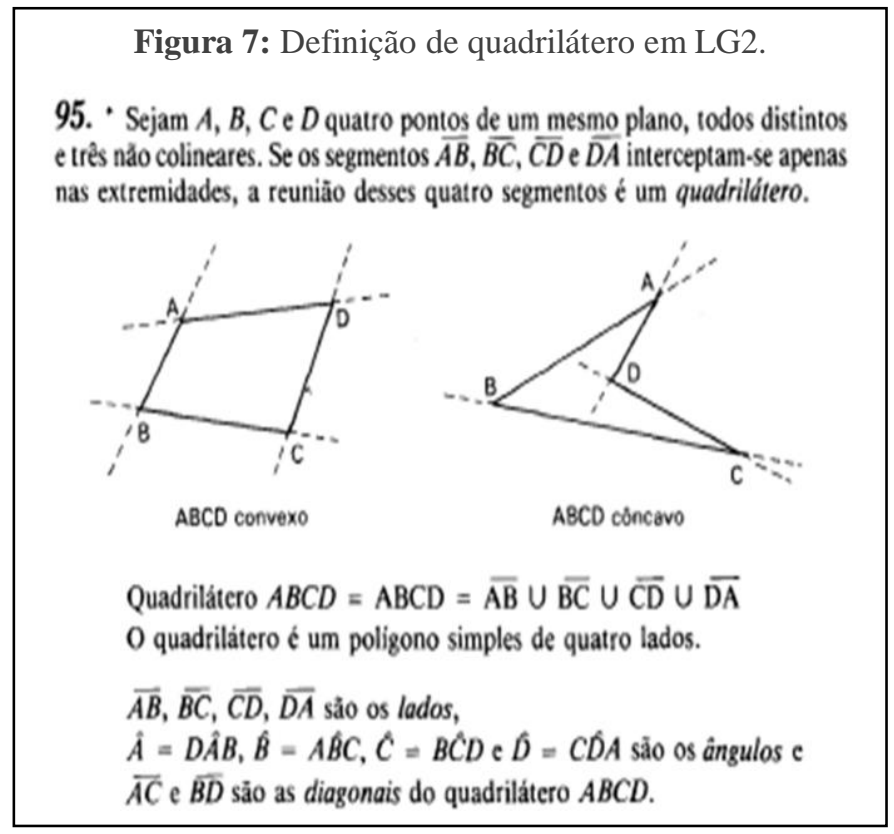

Fonte: LG2 (p. 99, apud FERREIRA, 2016, p.118).

Quanto aos elementos dos quadriláteros (ângulos, vértices, lados e diagonais), em LG1 e LG3 são abordados no tópico referente a polígonos, embora apenas LG3 esclareça o significado de lados e ângulos opostos e consecutivos do quadrilátero. Esse esclarecimento se faz necessário, uma vez que é requerido nas propriedades dos quadriláteros.

Com relação a $\mathrm{T}_{2}\left(\mathrm{Q}_{2}\right)$, nenhuma das obras apresenta a demonstração. LG1 traz o enunciado como um corolário da soma dos ângulos internos do triângulo e propõe a demonstração como exercício. LG2 traz apenas o enunciado e LG3 não se refere a essa propriedade, mas apresenta a soma dos ângulos internos de um polígono qualquer.

As tarefas $\mathrm{T}_{1}\left(\mathrm{Q}_{2}\right)$ e $\mathrm{T}_{2}\left(\mathrm{Q}_{2}\right)$ têm por objetivo evidenciar a forma como o conteúdo 'quadriláteros' foi introduzido em cada livro e qual foi a definição adotada. Observamos que, especialmente nos livros indicados para a graduação, 'quadriláteros' foi abordado como um conteúdo já conhecido pelos alunos e a demonstração da soma dos ângulos internos foi 
proposta como exercício, supondo que os alunos estejam aptos a demonstrá-la, ou deixada de vez a cargo do professor.

Apresentamos a questão Q3 a seguir:

Questão $3\left(Q_{3}\right)$ : Como o autor classifica e define os diferentes tipos de quadriláteros?

Quadro 5: Tarefas relacionadas com a questão

\begin{tabular}{|c|c|}
\hline Tarefas identificadas & Técnica associadas \\
\hline $\begin{array}{l}\mathrm{T}_{1} \mathbf{Q}_{3}: \text { Apresentar a classificação dos } \\
\text { quadriláteros. }\end{array}$ & $\begin{array}{l}t_{1}\left(\mathrm{~T}_{1} \mathrm{Q}_{3}\right): \text { Como um tópico do conteúdo } \\
\text { quadrilátero. } \\
t_{2}\left(\mathrm{~T}_{1} \mathrm{Q}_{3}\right) \text { : Incluído na seção de exercícios. } \\
t_{3}\left(\mathrm{~T}_{1} \mathrm{Q}_{3}\right) \text { : Utilizando diferentes registros de } \\
\text { representação. } \\
t_{4}\left(\mathrm{~T}_{1} \mathrm{Q}_{3}\right) \text { : Utilizando diagrama. }\end{array}$ \\
\hline$T_{2} Q_{3}$ : Definir paralelogramo. & $\begin{array}{l}t_{1}\left(\mathrm{~T}_{2} \mathrm{Q}_{3}\right): \text { Utilizando o paralelismo dos lados. } \\
t_{2}\left(\mathrm{~T}_{2} \mathrm{Q}_{3}\right): \text { Utilizando uma caracterizaçãa do } \\
\text { paralelogramo. } \\
t_{3}\left(\mathrm{~T}_{2} \mathrm{Q}_{3}\right): \text { Utilizando diferentes registros de } \\
\text { representação. }\end{array}$ \\
\hline$T_{3} Q_{3}$ : Definir retângulo, losango e quadrado. & $\begin{array}{l}t_{1}\left(\mathrm{~T}_{3} \mathrm{Q}_{3}\right) \text { : Utilizando a definição de paralelogramo } \\
\text { e congruência de lados e/ou ângulos. } \\
t_{2}\left(\mathrm{~T}_{3} \mathrm{Q}_{3}\right) \text { : Utilizando a congruência de lados e/ou } \\
\text { angulos. } \\
t_{3}\left(\mathrm{~T}_{3} \mathrm{Q}_{3}\right) \text { : Utilizando diferentes registros de } \\
\text { representação. }\end{array}$ \\
\hline$T_{4} Q_{3}$ : Definir trapézio. & $\begin{array}{l}t_{1}\left(\mathrm{~T}_{4} \mathrm{Q}_{3}\right) \text { : Utilizando apenas um par de lados } \\
\text { paralelos. } \\
t_{2}\left(\mathrm{~T}_{4} \mathrm{Q}_{3}\right) \text { : Utilizando um par de lados paralelos. }\end{array}$ \\
\hline
\end{tabular}

Fonte: Construção nossa

$[\theta / \Theta]_{3}$ : $\mathrm{O}$ discurso teórico-tecnológico associado às tarefas $T_{1} Q_{3}, T_{2} Q_{3}$ e $T_{3} Q_{3}$ consiste nas definições de paralelogramo, retângulo, losango, quadrado e trapézio.

As tarefas $\mathrm{T}_{1} \mathrm{Q}_{3}, \mathrm{~T}_{2} \mathrm{Q}_{3}, \mathrm{~T}_{3} \mathrm{Q}_{3}$ e $\mathrm{T}_{4} \mathrm{Q}_{3}$ visam observar como a classificação dos quadriláteros é apresentada. As técnicas $t_{1}\left(\mathrm{~T}_{1} \mathrm{Q}_{3}\right)$ e $t_{2}\left(\mathrm{~T}_{1} \mathrm{Q}_{3}\right)$ prestam-se a apontar a forma com que os autores apresentam a classificação (se em um tópico específico ou na seção de exercícios) e, ainda, quais registros de representação semiótica são utilizados para essa classificação. Com a técnica $t_{4}\left(\mathrm{~T}_{1} \mathrm{Q}_{3}\right)$, verificamos se os autores utilizam diagramas para relacionar os quadriláteros.

As técnicas $t_{1}\left(\mathrm{~T}_{2} \mathrm{Q}_{3}\right)$ e $t_{2}\left(\mathrm{~T}_{2} \mathrm{Q}_{3}\right)$ nos permitiram analisar se os autores utilizam as caracterizações do paralelogramo para defini-lo. Ao utilizar $t_{1}\left(\mathrm{~T}_{2} \mathrm{Q}_{3}\right)$, o autor define paralelogramo como o quadrilátero que possui os lados opostos paralelos; ao optar por $t_{2}\left(\mathrm{~T}_{2} \mathrm{Q}_{3}\right)$, utiliza uma caracterização do paralelogramo para defini-lo - por exemplo: $(a)$ um quadrilátero convexo que tem dois lados opostos paralelos e congruentes é um paralelogramo; (b) um quadrilátero cujas diagonais se interceptam em seus pontos médios é um paralelogramo; (c) um quadrilátero que tem seus lados opostos congruentes é um 
paralelogramo; $(d)$ um quadrilátero que possui os ângulos opostos congruentes é um paralelogramo.

As técnicas $t_{1}\left(\mathrm{~T}_{3} \mathrm{Q}_{3}\right)$ e $t_{2}\left(\mathrm{~T}_{3} \mathrm{Q}_{3}\right)$ nos permitiram analisar se os autores descrevem retângulo, quadrado e losango utilizando condições mínimas - por exemplo, se para definir retângulo, uma das seguintes definições foi adotada: (a) é um quadrilátero que tem seus ângulos congruentes; $(b)$ é um paralelogramo que tem um ângulo reto; $(c)$ é um paralelogramo que tem dois lados consecutivos perpendiculares; (d) é um paralelogramo cujos ângulos consecutivos são congruentes.

O quadrado pode ser definido como sendo: (a) um retângulo em que os lados consecutivos congruentes ou (b) um retângulo cujas diagonais são congruentes.

O losango pode ser definido como sendo: (a) um paralelogramo cujos lados consecutivos são congruentes ou $(b)$ um paralelogramo cujas diagonais são perpendiculares.

Com a tarefa $\mathrm{T}_{4} \mathrm{Q}_{3}$ e as técnicas $t_{1}\left(\mathrm{~T}_{4} \mathrm{Q}_{3}\right)$ e $t_{2}\left(\mathrm{~T}_{4} \mathrm{Q}_{3}\right)$, verificamos se a definição adotada para trapézio foi coerente com as propriedades abordadas pelos autores para esse grupo de quadriláteros. Admitindo a técnica $t_{1}\left(\mathrm{~T}_{4} \mathrm{Q}_{3}\right)$, o trapézio é o quadrilátero que possui exatamente um par de lados paralelos (chamados bases, enquanto os outros dois são os lados não bases). Segundo a técnica $t_{2}\left(\mathrm{~T}_{4} \mathrm{Q}_{3}\right)$, trapézio é o quadrilátero que possui um par de lados paralelos; neste caso o paralelogramo é um trapézio, ou seja, o paralelogramo é um trapézio isósceles. Essa escolha solicita uma reestruturação da definição de trapézio isósceles ou de suas propriedades. Caso contrário, não poderíamos mais admitir a propriedade que afirma que os ângulos da base de um trapézio isósceles são congruentes.

O Quadro 6 sumariza os resultados dessas tarefas.

Quadro 6: Análise referente da questão 3 (Q3).

\begin{tabular}{|c|c|c|c|c|}
\hline & & LG1 & LG2 & LG3 \\
\hline \multirow{4}{*}{$\mathrm{T}_{1}$} & $t_{1}\left(\mathrm{~T}_{1} \mathrm{Q}_{3}\right)$ & & $\checkmark$ & $\checkmark$ \\
\hline & $t_{2}\left(\mathrm{~T}_{1} \mathrm{Q}_{3}\right)$ & $\checkmark$ & & \\
\hline & $t_{3}\left(\mathrm{~T}_{1} \mathrm{Q}_{3}\right)$ & & $\checkmark$ & $\checkmark$ \\
\hline & $t_{4}\left(\mathrm{~T}_{1} \mathrm{Q}_{3}\right)$ & & & \\
\hline \multirow{3}{*}{$\mathrm{T}_{2}$} & $t_{1}\left(\mathrm{~T}_{2} \mathrm{Q}_{3}\right)$ & $\checkmark$ & $\checkmark$ & $\checkmark$ \\
\hline & $t_{2}\left(\mathrm{~T}_{2} \mathrm{Q}_{3}\right)$ & & & \\
\hline & $t_{3}\left(\mathrm{~T}_{2} \mathrm{Q}_{3}\right)$ & $\checkmark$ & $\checkmark$ & $\checkmark$ \\
\hline \multirow{3}{*}{$\mathrm{T}_{3}$} & $t_{1}\left(\mathrm{~T}_{3} \mathrm{Q}_{3}\right)$ & & & $\checkmark$ \\
\hline & $t_{2}\left(\mathrm{~T}_{3} \mathrm{Q}_{3}\right)$ & $\checkmark$ & $\checkmark$ & \\
\hline & $t_{3}\left(\mathrm{~T}_{3} \mathrm{Q}_{3}\right)$ & & $\checkmark$ & $\checkmark$ \\
\hline \multirow[t]{2}{*}{$\mathrm{T}_{4}$} & $t_{1}\left(\mathrm{~T}_{4} \mathrm{Q}_{3}\right)$ & & & \\
\hline & $t_{2}\left(\mathrm{~T}_{4} \mathrm{Q}_{3}\right)$ & $\checkmark$ & $\checkmark$ & $\checkmark$ \\
\hline
\end{tabular}

Fonte: Ferreira (2016, p.120). 
Com relação à tarefa $\mathrm{T}_{1} \mathrm{Q}_{3}$, apenas $\mathrm{LG1}$ apresenta a classificação dos quadriláteros na seção de exercícios, e o faz utilizando apenas um tipo de registro - o discursivo - para definir esse polígono.

LG2 e LG3 abordam o conteúdo 'quadriláteros' na seção destinada ao desenvolvimento da teoria e utilizam mais de um registro para definir as classes de quadriláteros, sendo que apenas LG2 utiliza simultaneamente os registros em língua natural, figural e simbólico.

Nenhum dos autores utiliza diagramas para relacionar os quadriláteros de acordo com suas propriedades.

Os três livros definem paralelogramo como o quadrilátero que possui lados opostos paralelos. Para representá-lo, utilizam o registro em língua natural e o figural. Apenas LG2 representa este quadrilátero utilizando os três registros simultaneamente.

Quanto a $\mathrm{T}_{3} \mathrm{Q}_{3}$, LG1 utiliza condições mínimas para definir losango, retângulo e quadrado e emprega os três registros de representação para definir esses quadriláteros. LG2 também utiliza condições mínimas, exceto para o losango, e faz uso apenas do registro em língua natural para definir esses quadriláteros. Apenas LG3 não utiliza condições mínimas para definir retângulo, losango e quadrado, mas emprega a representação discursiva e a figural em suas definições.

A tarefa $\mathrm{T}_{4} \mathrm{Q}_{3}$ foi executada nos três livros com a técnica $t_{2}\left(\mathrm{~T}_{3} \mathrm{Q}_{3}\right)$, ou seja, os três consideram que o paralelogramo é um trapézio. Ao analisar a definição de trapézio isósceles, observamos que nenhuma das três obras recorre a alguma restrição, o que indica que nas três o paralelogramo é um trapézio isósceles e, portanto, o retângulo, o losango e o quadrado também estão contidos no grupo dos trapézios isósceles.

No âmbito da questão 3, observamos mais uma vez que a forma como o conteúdo 'quadriláteros' é abordado nos três livros, especialmente LG1 e LG3, indica que os autores esperam que seus leitores disponham de algum conhecimento prévio sobre esse objeto.

\section{Questão $4\left(Q_{4}\right)$ : Como o autor aborda as propriedades dos quadriláteros?}

Nesta questão, subdividimos algumas tarefas em subtarefas, visto que não existe apenas uma propriedade para cada grupo de quadriláteros. Representamos as subtarefas referentes à tarefa $\mathrm{T}_{\mathrm{i}} \mathrm{Q}_{\mathrm{j}}$ por $\mathrm{T}_{\mathrm{ki}} \mathrm{Q}_{\mathrm{j}}$ : subtarefa $k$ referente à tarefa $i$ da questão $j$. As tarefas referentes às subtarefas $\mathrm{T}_{\mathrm{ki}} \mathrm{Q}_{\mathrm{j}}$, por sua vez, foram representadas por $t_{\mathrm{n}}\left(\mathrm{T}_{\mathrm{ki}} \mathrm{Q}_{\mathrm{j}}\right)$, onde $n, k, i$ e $j$ são naturais não nulos. No quadro 7, apresentamos as subtarefas relacionadas à tarefa $\mathrm{T}_{1} \mathrm{Q}_{4}$ e as técnicas que cumprem essa tarefa e subtarefas a ela relacionadas. 
Quadro 7: Tarefas e técnicas relacionadas à $\mathrm{Q}_{4}$

\begin{tabular}{|c|c|}
\hline Tarefas relacionadas à questão $\mathbf{Q}_{4}$ & Técnicas que cumprem essas tarefas \\
\hline $\begin{array}{l}\mathrm{T}_{1} \mathrm{Q}_{4}: \quad \text { Apresentar as propriedades dos } \\
\text { paralelogramos }\end{array}$ & $\begin{array}{l}t_{1}\left(\mathrm{~T}_{1} \mathrm{Q}_{4}\right): \text { Observação de propriedades que } \\
\text { caracterizam o paralelogramo, validando-as com } \\
\text { demonstrações. }\end{array}$ \\
\hline $\begin{array}{l}\mathrm{T}_{11} \mathrm{Q}_{4} \text { : Enunciar e demonstrar que os ângulos } \\
\text { opostos de um paralelogramo são congruentes e } \\
\text { os consecutivos são suplementares }\end{array}$ & $\begin{array}{l}t_{1}\left(\mathrm{~T}_{11} \mathrm{Q}_{4}\right) \text { : Utilizar o teorema das paralelas cortadas } \\
\text { por uma transversal e congruência de triângulos } \\
\text { (caso ângulo-lado-ângulo). } \\
t_{2}\left(\mathrm{~T}_{11} \mathrm{Q}_{4}\right) \text { : Utilizar o teorema das paralelas cortadas } \\
\text { por uma transversal e a transitividade da } \\
\text { igualdade. } \\
t_{3}\left(\mathrm{~T}_{11} \mathrm{Q}_{4}\right) \text { : Apenas enunciar a propriedade, sem } \\
\text { demonstrá-la. } \\
t_{4}\left(\mathrm{~T}_{11} \mathrm{Q}_{4}\right) \text { : Propor a propriedade como exercício }\end{array}$ \\
\hline $\begin{array}{lrrrr}\mathrm{T}_{21} \mathrm{Q}_{4}: & \text { Enunciar } & \text { e demonstrar } & \text { que o } \\
\text { quadrilátero } & \text { que } & \text { possui ângulos opostos } \\
\text { congruentes } & \text { ou } & \text { ângulos consecutivos } \\
\text { suplementares é um paralelogramo } & \end{array}$ & $\begin{array}{l}t_{1}\left(\mathrm{~T}_{21} \mathrm{Q}_{4}\right) \text { : Utilizar o teorema das paralelas cortadas } \\
\text { por uma transversal e a soma dos ângulos internos } \\
\text { do quadrilátero. } \\
t_{2}\left(\mathrm{~T}_{21} \mathrm{Q}_{4}\right) \text { : Apenas enunciar a propriedade, sem } \\
\text { demonstrá-la. } \\
t_{3}\left(\mathrm{~T}_{21} \mathrm{Q}_{4}\right) \text { : Propor a propriedade como exercício. }\end{array}$ \\
\hline $\begin{array}{l}T_{31} Q_{4}: \text { Enunciar e demonstrar que os lados } \\
\text { opostos de um paralelogramo são congruentes. }\end{array}$ & $\begin{array}{l}t_{1}\left(\mathrm{~T}_{31} \mathrm{Q}_{4}\right) \text { : Utilizar o teorema das paralelas cortadas } \\
\text { por uma transversal e a congruência de triângulos. } \\
t_{2}\left(\mathrm{~T}_{31} \mathrm{Q}_{4}\right) \text { : Apenas enunciar a propriedade, sem } \\
\text { demonstrá-la. } \\
t_{3}\left(\mathrm{~T}_{31} \mathrm{Q}_{4}\right) \text { : Propor a propriedade como exercício. }\end{array}$ \\
\hline $\begin{array}{l}\mathrm{T}_{41} \mathrm{Q}_{4} \text { : Enunciar e demonstrar que todo } \\
\text { quadrilátero que possui lados opostos } \\
\text { congruentes é paralelogramo. }\end{array}$ & $\begin{array}{l}t_{1}\left(\mathrm{~T}_{41} \mathrm{Q}_{4}\right) \text { : Utilizar congruência de triângulos. } \\
t_{2}\left(\mathrm{~T}_{41} \mathrm{Q}_{4}\right) \text { : Apenas enunciar a propriedade, sem } \\
\text { demonstrá-la. } \\
t_{3}\left(\mathrm{~T}_{41} \mathrm{Q}_{4}\right) \text { : Propor a propriedade como exercício. }\end{array}$ \\
\hline $\begin{array}{l}\mathrm{T}_{51} \mathrm{Q}_{4} \text { : Enunciar e demonstrar que em todo } \\
\text { paralelogramo as diagonais interceptam-se em } \\
\text { seus respectivos pontos médios }\end{array}$ & $\begin{array}{l}t_{1}\left(\mathrm{~T}_{51} \mathrm{Q}_{4}\right) \text { : Utilizar o teorema das paralelas cortadas } \\
\text { por uma transversal, a propriedade dos lados } \\
\text { opostos do paralelogramo e a congruência de } \\
\text { triângulos. } \\
t_{2}\left(\mathrm{~T}_{51} \mathrm{Q}_{4}\right) \text { : Apenas enunciar a propriedade, sem } \\
\text { demonstrá-la. } \\
t_{3}\left(\mathrm{~T}_{51} \mathrm{Q}_{4}\right) \text { : Propor a propriedade como exercício }\end{array}$ \\
\hline $\begin{array}{l}\mathrm{T}_{61} \mathrm{Q}_{4} \text { : Enunciar e demonstrar que todo } \\
\text { quadrilátero em que as diagonais se } \\
\text { interceptam em seus respectivos pontos médios } \\
\text { é paralelogramo }\end{array}$ & $\begin{array}{l}t_{1}\left(\mathrm{~T}_{61} \mathrm{Q}_{4}\right) \text { : Utilizar o teorema das paralelas cortadas } \\
\text { por uma transversal, a propriedade dos ângulos } \\
\text { opostos pelo vértice e a congruência de triângulos. } \\
t_{2}\left(\mathrm{~T}_{61} \mathrm{Q}_{4}\right) \text { : Apenas enunciar a propriedade, sem } \\
\text { demonstrá-la. } \\
t_{3}\left(\mathrm{~T}_{61} \mathrm{Q}_{4}\right) \text { : Propor a propriedade como exercício }\end{array}$ \\
\hline $\begin{array}{l}\mathrm{T}_{71} \mathbf{Q}_{4} \text { : Enunciar e demonstrar que todo } \\
\text { quadrilátero convexo que possui dois lados } \\
\text { opostos paralelos e congruentes é } \text { em } \\
\text { paralelogramo }\end{array}$ & $\begin{array}{l}t_{1}\left(\mathrm{~T}_{71} \mathrm{Q}_{4}\right) \text { : Utilizar o teorema das paralelas cortadas } \\
\text { por uma transversal e a congruência de triângulos. } \\
t_{2}\left(\mathrm{~T}_{71} \mathrm{Q}_{4}\right) \text { : Apenas enunciar a propriedade, sem } \\
\text { demonstrá-la. } \\
t_{3}\left(\mathrm{~T}_{71} \mathrm{Q}_{4}\right) \text { : Propor a propriedade como exercício }\end{array}$ \\
\hline
\end{tabular}

Fonte: Construção nossa

$[\theta / \Theta]\left(\mathrm{T}_{1} \mathrm{Q}_{4}\right)$ : $\mathrm{O}$ discurso teórico-tecnológico associado à tarefa $\mathrm{T}_{1} \mathrm{Q}_{4}$ consiste em: teorema das paralelas cortados por uma transversal, soma dos ângulos internos de um quadrilátero, congruência de triângulos, transitividade da relação de igualdade, definição de paralelogramo, definição de diagonal, propriedades do paralelogramo, definição de ponto médio e propriedade dos ângulos opostos pelo vértice. 
Utilizando as duas últimas técnicas de cada subtarefa, o livro apenas enuncia a propriedade, sendo que, utilizando a última técnica, a demonstração da propriedade é proposta como exercício para o aluno.

Seguem-se as demonstrações, efetuadas segundo as técnicas propostas para cada subtarefa.

$\mathrm{T}_{11} \mathrm{Q}_{4}$ : Enunciar e demonstrar que os ângulos opostos de um paralelogramo são congruentes e os consecutivos são suplementares.

As técnicas $t_{1}\left(\mathrm{~T}_{11} \mathrm{Q}_{4}\right)$ e $t_{2}\left(\mathrm{~T}_{11} \mathrm{Q}_{4}\right)$ se distinguem pelo fato de apenas a primeira utilizar congruência de triângulos, embora as duas utilizem o teorema das paralelas. Seguem-se as demonstrações segundo cada técnica.

\section{Demonstração segundo a técnica $t_{1}\left(\mathrm{~T}_{11} \mathrm{Q}_{4}\right)$ :}

$t_{1}\left(\mathrm{~T}_{11} \mathrm{Q}_{4}\right)$ : Utilizar o teorema das paralelas cortadas por uma transversal e congruência de triângulos (caso ângulo-lado-ângulo) (Figura 19).

Figura 8: Figura-suporte para a demonstração de que os ângulos opostos de um paralelogramo são congruentes e os consecutivos são suplementares, segundo a técnica $\mathrm{t}_{1}\left(\mathrm{~T}_{11} \mathrm{Q}_{4}\right)$

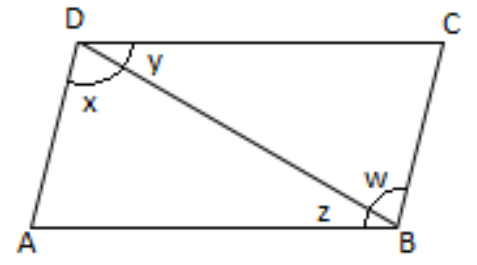

Fonte: Ferreira (2016, p.124)

Hipótese: $A B C D$ é paralelogramo

Tese: Os ângulos opostos são congruentes, isto é, $\hat{A} \equiv \hat{C}$ e $\widehat{D} \equiv \widehat{B}$

Os ângulos consecutivos são suplementares, isto, é, $\operatorname{med}(\hat{A})+\operatorname{med}(\widehat{D})=\operatorname{med}(\widehat{B})+$ $\operatorname{med}(\hat{C})=180^{\circ}$ e $\operatorname{med}(\hat{A})+\operatorname{med}(\widehat{B})=\operatorname{med}(\widehat{D})+\operatorname{med}(\hat{C})=180^{\circ}$

\section{Demonstração:}

A diagonal $\overline{B D}$ divide o paralelogramo $A B C D$ em dois triângulos: $A B D$ e $B C D$. Como os lados opostos do paralelogramo são paralelos, pelo teorema das paralelas, $\hat{x}=A \widehat{D} B \equiv$ $D \widehat{B} C=\widehat{w}$ e $\hat{y}=C \widehat{D} B \equiv A \widehat{B} D=\hat{z}$ (ângulos alternos internos). Destas igualdades observamos que med $(A \widehat{D} C)=x+y=w+z=\operatorname{med}(A \widehat{B} C)$. Logo, $\widehat{D} \equiv \widehat{B}$.

Comparando os triângulos $A B D$ e $B C D$, tem-se: $\hat{x} \equiv \widehat{w}, \overline{B D}$ lado comum e $\hat{y} \equiv \hat{z}$. Pelo caso ângulo-lado-ângulo de congruência de triângulos, esses triângulos são congruentes e, portanto, $\hat{A} \equiv \hat{C}$. 
Ainda pelo teorema das paralelas, $\operatorname{med}(\hat{A})+\operatorname{med}(\widehat{D})=\operatorname{med}(\widehat{B})+\operatorname{med}(\hat{C})=180^{\circ}$ e $\operatorname{med}(\hat{A})+\operatorname{med}(\widehat{B})=\operatorname{med}(\widehat{D})+\operatorname{med}(\hat{C})=180^{\circ}$. Logo, os ângulos consecutivos são suplementares.

\section{Demonstração segundo a técnica $t_{2}\left(\mathrm{~T}_{11} \mathrm{Q}_{4}\right)$ :}

$t_{2}\left(\mathrm{~T}_{11} \mathrm{Q}_{4}\right)$ : Utilizando o teorema das paralelas cortadas por uma transversal e a transitividade da igualdade (Figura 20).

Figura 9: Figura-suporte para a demonstração de que os ângulos opostos de um paralelogramo são congruentes e os consecutivos são suplementares, segundo $\mathrm{t}_{2}\left(\mathrm{~T}_{11} \mathrm{Q}_{4}\right)$.

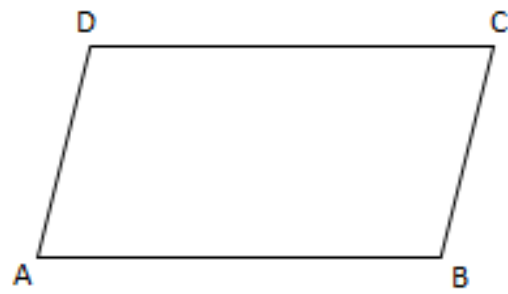

Fonte: Ferreira (2016, p.125)

Hipótese: $A B C D$ é paralelogramo

Tese: $[\hat{A} \equiv \hat{C}, \hat{B} \equiv \widehat{D}$;

$\operatorname{med}(\hat{A})+\operatorname{med}(\widehat{D})=\operatorname{med}(\hat{B})+\operatorname{med}(\hat{C})=180^{\circ} \quad$ e $\quad \operatorname{med}(\hat{A})+\operatorname{med}(\widehat{B})=$ $\operatorname{med}(\widehat{D})+\operatorname{med}(\hat{C})=180^{\circ}$

\section{Demonstração:}

Como os lados opostos do paralelogramo são paralelos, pelo teorema das paralelas, temos: $\operatorname{med}(\hat{A})+\operatorname{med}(\widehat{B})=180^{\circ}$ e $\operatorname{med}(\hat{B})+\operatorname{med}(\hat{C})=180^{\circ}$. Daí segue-se que $\operatorname{med}(\hat{A})+$ $\operatorname{med}(\widehat{B})=\operatorname{med}(\widehat{B})+\operatorname{med}(\hat{C})$ e, portanto, $\hat{A} \equiv \hat{C}$. De modo análogo, mostra-se que $\hat{B} \equiv$ $\widehat{D}$.

Ainda pelo teorema das paralelas, $\operatorname{med}(\hat{A})+\operatorname{med}(\widehat{D})=\operatorname{med}(\hat{B})+\operatorname{med}(\hat{C})=180^{\circ} \mathrm{e}$ $\operatorname{med}(\hat{A})+\operatorname{med}(\widehat{B})=\operatorname{med}(\widehat{D})+\operatorname{med}(\hat{C})=180^{\circ}$. Logo, os ângulos consecutivos são suplementares.

\section{$T_{21} Q_{4}$ : Enunciar e demonstrar que $o$ quadrilátero que possui ângulos opostos congruentes ou ângulos consecutivos suplementares é um paralelogramo.}

$t_{1}\left(\mathrm{~T}_{21} \mathrm{Q}_{4}\right)$ : Utilizar o teorema das paralelas cortadas por uma transversal e a soma dos ângulos internos do quadrilátero (Figura 10). 
Figura 10: Figura-suporte para a demonstração da tarefa $T_{21} Q_{4}$ segundo a técnica $t_{2}\left(T_{21} Q_{4}\right)$.

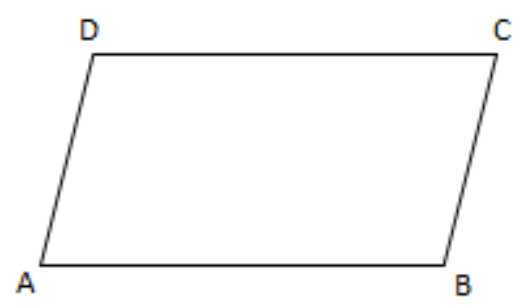

Fonte: Ferreira (2016, p. 125)

Hipótese: Os ângulos opostos do quadrilátero $A B C D$ são congruentes, isto é, $\hat{A}=\hat{C}$ e $\widehat{B}=\widehat{D}$. Tese: O quadrilátero $A B C D$ é um paralelogramo.

\section{Demonstração:}

$\hat{A} \equiv \hat{C}$ e $\hat{B} \equiv \widehat{D} \Rightarrow \operatorname{med}(\hat{A})+\operatorname{med}(\widehat{B})=\operatorname{med}(\hat{C})+\operatorname{med}(\widehat{D})$.

$\operatorname{med}(\hat{A})+\operatorname{med}(\widehat{B})+\operatorname{med}(\hat{C})+\operatorname{med}(\widehat{D})=360^{\circ} \Rightarrow 2[\operatorname{med}(\hat{A})+\operatorname{med}(\hat{B})]=$ $360^{\circ} \Rightarrow \operatorname{med}(\hat{A})+\operatorname{med}(\widehat{B})=180^{\circ}$.

Se $\overline{A D}$ e $\overline{B C}$ são cortadas por uma transversal $\overline{A B}$, sendo que $\hat{A}$ e $\hat{B}$ são suplementares, então $\overline{A D}$ e $\overline{B C}$ são paralelas. De modo análogo, $\overline{A B}$ e $\overline{C D}$ são paralelas. Logo, $A B C D$ é um paralelogramo.

Mostramos que um quadrilátero que possui ângulos opostos congruentes é um paralelogramo. Vamos mostrar que um quadrilátero que possui ângulos consecutivos suplementares é um paralelogramo.

Ainda considerando a Figura 10.

Hipótese: Os ângulos consecutivos do quadrilátero $A B C D$ são suplementares, ou seja:

$$
\begin{gathered}
\operatorname{med}(\hat{A})+\operatorname{med}(\widehat{B})=\operatorname{med}(\widehat{B})+\operatorname{med}(\hat{C})=\operatorname{med}(\hat{C})+\operatorname{med}(\widehat{D})=\operatorname{med}(\widehat{D})+\operatorname{med}(\hat{A}) \\
=180^{\circ}
\end{gathered}
$$

Tese: $A B C D$ é um paralelogramo.

\section{Demonstração:}

$\operatorname{Se} \quad \operatorname{med}(\hat{A})+\operatorname{med}(\widehat{B})=\operatorname{med}(\widehat{B})+\operatorname{med}(\hat{C})=\operatorname{med}(\hat{C})+\operatorname{med}(\widehat{D})=\operatorname{med}(\widehat{D})+$ $\operatorname{med}(\hat{A})=180^{\circ}$, então, pelo teorema das paralelas, $\overline{A B} / / \overline{D C}$ e $\overline{A D} / / \overline{B C}$. Logo, $A B C D$ é um paralelogramo.

\section{$T_{31} Q_{4}$ : Enunciar e demonstrar que os lados opostos de um paralelogramo são congruentes.}

$t_{1}\left(\mathrm{~T}_{31} \mathrm{Q}_{4}\right)$ : Utilizar o teorema das paralelas cortadas por uma transversal e a congruência de triângulos. 
Figura 11: Figura-suporte para a demonstração da tarefa $T_{31} Q_{4}$ segundo a técnica $t_{1}\left(T_{31} Q_{4}\right)$.

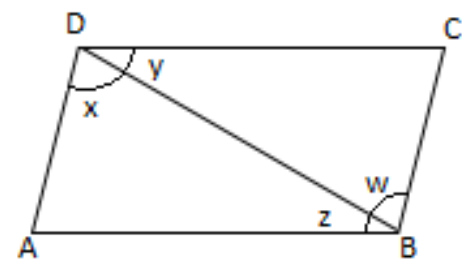

Fonte: Ferreira (2016, p.126)

Hipótese: $A B C D$ é paralelogramo

Tese: Os lados opostos são congruentes, ou seja, $A B=D C$ e $A D=B C$.

Demonstração:

A diagonal $\overline{B D}$ divide o paralelogramo $A B C D$ em dois triângulos: $A B D$ e $B C D$. Como os lados opostos do paralelogramo são paralelos, pelo teorema das paralelas, $\widehat{x} \equiv A \widehat{D} B \equiv$ $D \widehat{B} C \equiv \widehat{w}$ e $\hat{y} \equiv C \widehat{D} B \equiv A \widehat{B} D \equiv \hat{z}$ (ângulos alternos internos).

Comparando os triângulos $A B D$ e $B C D$ tem-se: $\hat{x} \equiv \widehat{w}, \overline{B D}$ lado comum e $\hat{y} \equiv \hat{z}$. Pelo caso ângulo-lado-ângulo de congruência de triângulos, esses triângulos são congruentes e, portanto, $A B=C D$ e $A D=B C$.

$\mathrm{T}_{41} \mathrm{Q}_{4}$ : Enunciar e demonstrar que todo quadrilátero que possui lados opostos congruentes é paralelogramo.

$t_{1}\left(\mathrm{~T}_{41} \mathrm{Q}_{4}\right)$ : Utilizar congruência de triângulos.

Figura 12: Figura-suporte para a demonstração da tarefa $T_{41} Q_{4}$ segundo a técnica $t_{1}\left(T_{41} Q_{4}\right)$.

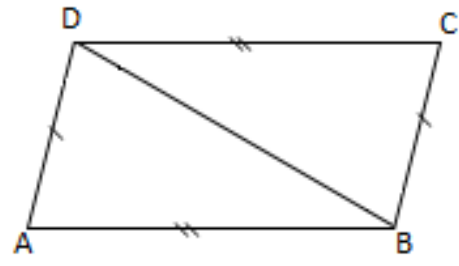

Fonte: Ferreira (2016, p.127).

Hipótese: $A D=B C$ e $A B=D C$

Tese: $A B C D$ é paralelogramo

\section{Demonstração:}

Considerando os triângulos $A B D$ e $B C D$, tem-se, por hipótese, que $A D=B C$ e $A B=D C$. Além disso, $\overline{B D}$ é lado comum. Logo, pelo caso de congruência lado-lado-lado, esses triângulos são congruentes e, portanto, $A \widehat{D} B \equiv D \widehat{B} C$ e $A \widehat{B} D \equiv B \widehat{D} C$. Pelo teorema das paralelas, $\overline{A D} / / \overline{B C}$ e $\overline{A B} / / \overline{D C}$. Podemos concluir então que $A B C D$ é paralelogramo. 
$T_{51} Q_{4}$ : Enunciar e demonstrar que em todo paralelogramo as diagonais interceptam-se em seus respectivos pontos médios.

$t_{1}\left(\mathrm{~T}_{51} \mathrm{Q}_{4}\right)$ : Utilizar o teorema das paralelas cortadas por uma transversal, a propriedade dos lados opostos do paralelogramo e a congruência de triângulos.

Figura 13: Figura-suporte para a demonstração da tarefa $T_{51} Q_{4}$ segundo a técnica $t_{1}\left(T_{51} Q_{4}\right)$

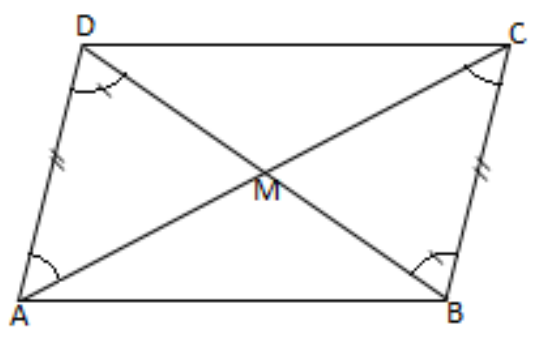

Fonte: Ferreira (2016, p.128).

Hipótese: $A B C D$ é paralelogramo, $\overline{\mathrm{AC}} \mathrm{e} \overline{\mathrm{BD}}$ são diagonais e $M$ é a interseção das diagonais $\overline{\mathrm{AC}}$ e $\overline{B D}$.

Tese: $M$ é ponto médio de $\overline{A C}$ e $\overline{B D}$, isto é, $A M=M C$ e $B M=M D$.

\section{Demonstração:}

As diagonais $\overline{A C}$ e $\overline{B D}$ dividem o paralelogramo $A B C D$ em quatro triângulos: $A M D, B M C$, $D M C$ e $A M B$. Considerando os triângulos $A M D$ e $B M C$, o fato de $A B C D$ ser um paralelogramo, tem-se: $A \widehat{D} M \equiv M \widehat{B} C$ (ângulos alternos internos); $A D=B C$ (lados opostos de um paralelogramo) e $D \hat{A} M \equiv M \hat{C} B$ (ângulos alternos internos).

Pelo caso de congruência ângulo-lado-ângulo, os triângulos $A M D$ e $B M C$ são congruentes. Logo, $A M=M C$ e $D M=M B$ e, portanto, $M$ é ponto médio de $A C$ e $B D$.

$T_{61} Q_{4}$ : Enunciar e demonstrar que todo quadrilátero em que as diagonais se interceptam em seus respectivos pontos médios é paralelogramo.

$t_{1}\left(\mathrm{~T}_{61} \mathrm{Q}_{4}\right)$ : Utilizar o teorema das paralelas cortadas por uma transversal, a propriedade dos ângulos opostos pelo vértice e a congruência de triângulos.

Figura 14: Figura-suporte para a demonstração da tarefa $T_{61} Q_{4}$ segundo a técnica $t_{1}\left(T_{61} Q_{4}\right)$

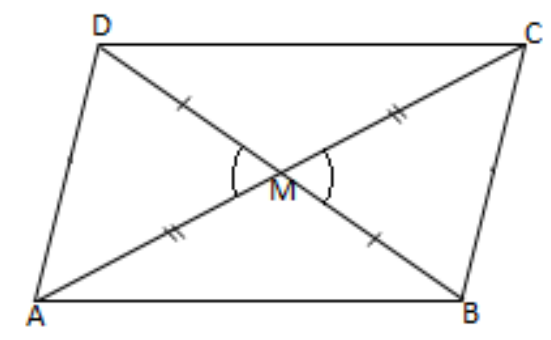

Fonte: Ferreira (2016, p.128). 
Hipótese: $A B C D$ é quadrilátero, $\overline{\mathrm{AC}}$ e $\overline{\mathrm{BD}}$ são diagonais e o ponto $M$, que é interseção das diagonais $\overline{\mathrm{AC}}$ e $\overline{B D}$, é ponto médio de ambas.

Tese: $A B C D$ é paralelogramo

\section{Demonstração:}

Considerando os triângulos $A M D$ e $B M C$ e o fato de $M$ ser ponto médio de $\overline{A C}$ e $\overline{B D}$, tem-se:

$D M=M B$ (onde $M$ é ponto médio de $\overline{D B}) ;$

$D \widehat{M} A \equiv C \widehat{M} B$ (ângulos opostos pelo vértice);

$A M=M C(M$ é ponto médio de $\overline{A C})$.

Pelo caso de congruência lado-ângulo-lado, os triângulos $A M D$ e $B M C$ são congruentes. Logo, $A \widehat{D} M \equiv M \widehat{B} C$ e portanto, pelo teorema das paralelas, $\overline{A D} / \overline{B C}$.

De modo análogo, mostra-se a congruência dos triângulos $D M C$ e $A M B$, o que implicará que $\overline{A B} / / \overline{C D}$, concluindo-se que $A B C D$ é um paralelogramo.

$\mathrm{T}_{71} \mathbf{Q}_{4}$ : Enunciar e demonstrar que todo quadrilátero que possui dois lados opostos paralelos e congruentes é um paralelogramo.

$t_{1}\left(\mathrm{~T}_{71} \mathrm{Q}_{4}\right)$ : Utilizar o teorema das paralelas cortadas por uma transversal e a congruência de triângulos.

Figura 15: Figura suporte para a demonstração da tarefa $T_{71} Q_{4}$ segundo a técnica $t_{1}\left(T_{71} Q_{4}\right)$.

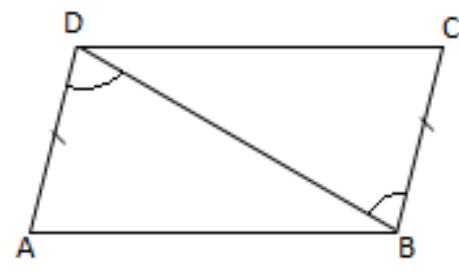

Fonte: Ferreira (2016, p.129).

Hipótese: $A B C D$ é quadrilátero, $\overline{B D}$ é diagonal e $\overline{\mathrm{AD}}$ é paralelo e congruente a $\overline{B C}$.

Tese: $A B C D$ é paralelogramo.

\section{Demonstração:}

A diagonal $\overline{B D}$ divide o quadrilátero $A B C D$ em dois triângulos: $A B D$ e $B C D$.

Considerando esses triângulos, tem-se: $A D=B C$ (hipótese).

$A \widehat{D} B \equiv D \widehat{B} C$ (hipótese e teorema das paralelas) e $\overline{B D}$ é lado comum.

Pelo caso de congruência lado-ângulo-lado, os triângulos $A B D$ e $B C D$ são congruentes. Logo, $A \widehat{B} D \equiv B \widehat{D} C$ e portanto, pelo teorema das paralelas, $\overline{A B} / \overline{D C}$. Podemos concluir então que $A B C D$ é um paralelogramo.

O Quadro 8 sumariza a análise correspondente à primeira tarefa da questão 4. 
Quadro 8: Análise referente à tarefa 1 da questão 4

\begin{tabular}{|c|c|c|c|c|c|}
\hline & & & LG1 & LG2 & LG3 \\
\hline \multirow{22}{*}{$\underset{-}{\stackrel{\Xi}{\Xi}}$} & \multirow{4}{*}{$\mathrm{T}_{11} \mathrm{Q}_{4}$} & $t_{1}\left(\mathrm{~T}_{11} \mathrm{Q}_{4}\right)$ & $\checkmark$ & & \\
\hline & & $t_{2}\left(\mathrm{~T}_{11} \mathrm{Q}_{4}\right)$ & & $\checkmark$ & \\
\hline & & $t_{3}\left(\mathrm{~T}_{11} \mathrm{Q}_{4}\right)$ & & & $\checkmark$ \\
\hline & & $t_{4}\left(\mathrm{~T}_{11} \mathrm{Q}_{4}\right)$ & & & \\
\hline & \multirow{3}{*}{$\mathrm{T}_{21} \mathrm{Q}_{4}$} & $t_{1}\left(\mathrm{~T}_{21} \mathrm{Q}_{4}\right)$ & & $\checkmark$ & \\
\hline & & $t_{2}\left(\mathrm{~T}_{21} \mathrm{Q}_{4}\right)$ & & & \\
\hline & & $t_{3}\left(\mathrm{~T}_{21} \mathrm{Q}_{4}\right)$ & $\checkmark$ & & \\
\hline & \multirow{3}{*}{$\mathrm{T}_{31} \mathrm{Q}_{4}$} & $t_{1}\left(\mathrm{~T}_{31} \mathrm{Q}_{4}\right)$ & $\checkmark$ & $\checkmark$ & \\
\hline & & $t_{2}\left(\mathrm{~T}_{31} \mathrm{Q}_{4}\right)$ & & & $\checkmark$ \\
\hline & & $t_{3}\left(\mathrm{~T}_{31} \mathrm{Q}_{4}\right)$ & & & \\
\hline & \multirow{3}{*}{$\mathrm{T}_{41} \mathrm{Q}_{4}$} & $t_{1}\left(\mathrm{~T}_{41} \mathrm{Q}_{4}\right)$ & $\checkmark$ & $\checkmark$ & \\
\hline & & $t_{2}\left(\mathrm{~T}_{41} \mathrm{Q}_{4}\right)$ & & & $\checkmark$ \\
\hline & & $t_{3}\left(\mathrm{~T}_{41} \mathrm{Q}_{4}\right)$ & & & \\
\hline & \multirow{3}{*}{$\mathrm{T}_{51} \mathrm{Q}_{4}$} & $t_{1}\left(\mathrm{~T}_{51} \mathrm{Q}_{4}\right)$ & & $\checkmark$ & \\
\hline & & $t_{2}\left(\mathrm{~T}_{51} \mathrm{Q}_{4}\right)$ & $\checkmark$ & & \\
\hline & & $t_{3}\left(\mathrm{~T}_{51} \mathrm{Q}_{4}\right)$ & $\checkmark$ & & $\checkmark$ \\
\hline & \multirow{3}{*}{$\mathrm{T}_{61} \mathrm{Q}_{4}$} & $t_{1}\left(\mathrm{~T}_{61} \mathrm{Q}_{4}\right)$ & & $\checkmark$ & \\
\hline & & $t_{2}\left(\mathrm{~T}_{61} \mathrm{Q}_{4}\right)$ & & & $\checkmark$ \\
\hline & & $t_{3}\left(\mathrm{~T}_{61} \mathrm{Q}_{4}\right)$ & $\checkmark$ & & $\checkmark$ \\
\hline & \multirow{3}{*}{$\mathrm{T}_{71} \mathrm{Q}_{4}$} & $t_{1}\left(\mathrm{~T}_{71} \mathrm{Q}_{4}\right)$ & & $\checkmark$ & \\
\hline & & $t_{2}\left(\mathrm{~T}_{71} \mathrm{Q}_{4}\right)$ & $\checkmark$ & & $\checkmark$ \\
\hline & & $t_{3}\left(\mathrm{~T}_{71} \mathrm{Q}_{4}\right)$ & & & \\
\hline
\end{tabular}

Fonte: Ferreira (2016, p.130).

No quadro 9, apresentamos as subtarefas relacionadas à tarefa $\mathrm{T}_{2} \mathrm{Q}_{4}$ e as técnicas que cumprem essa tarefa e subtarefas a ela relacionadas.

Quadro 9: Subtarefas relacionadas à tarefa $\mathrm{T}_{2} \mathrm{Q}_{4} \mathrm{e}$ as técnicas

\begin{tabular}{|c|c|}
\hline Tarefas & Técnicas \\
\hline $\begin{array}{l}\mathrm{T}_{2} \mathrm{Q}_{4}: \quad \text { Apresentar as propriedades dos } \\
\text { retângulos }\end{array}$ & $\begin{array}{llll}t_{1}\left(\mathrm{~T}_{2} \mathrm{Q}_{4}\right): \text { Observação de } & \text { propriedades } & \text { que } \\
\text { caracterizam o retângulo, } & \text { validando-as } & \text { com } \\
\text { demonstração } & & & \\
\end{array}$ \\
\hline $\begin{array}{l}\mathrm{T}_{12} \mathrm{Q}_{4}: \text { Enunciar e demonstrar que todo } \\
\text { retângulo é paralelogramo }\end{array}$ & $\begin{array}{l}t_{1}\left(\mathrm{~T}_{12} \mathrm{Q}_{4}\right): \text { Utilizar a propriedade das paralelas. } \\
t_{2}\left(\mathrm{~T}_{12} \mathrm{Q}_{4}\right) \text { : Utilizar as propriedades do } \\
\text { paralelogramo. } \\
t_{3}\left(\mathrm{~T}_{12} \mathrm{Q}_{4}\right): \text { Apenas enunciar, sem demonstrar. } \\
t_{4}\left(\mathrm{~T}_{12} \mathrm{Q}_{4}\right): \text { Apresentar a propriedade como } \\
\text { exercício. }\end{array}$ \\
\hline $\begin{array}{l}\mathrm{T}_{22} \mathrm{Q}_{4} \text { : Enunciar e demonstrar que em todo } \\
\text { retângulo as diagonais são congruentes }\end{array}$ & $\begin{array}{l}t_{1}\left(\mathrm{~T}_{22} \mathrm{Q}_{4}\right): \text { Assumir que o retângulo é } \\
\text { paralelogramo e utilizar a congruência de } \\
\text { triângulos. } \\
t_{2}\left(\mathrm{~T}_{22} \mathrm{Q}_{4}\right): \text { Apenas enunciar, sem demonstrar; } \\
t_{3}\left(\mathrm{~T}_{22} \mathrm{Q}_{4}\right): \text { Apresentar a propriedade como } \\
\text { exercício. }\end{array}$ \\
\hline $\begin{array}{l}\mathrm{T}_{32} \mathrm{Q}_{4}: \text { Enunciar e demonstrar } \\
\text { paralelogramo que todo } \\
\text { congruentes é um retângulo }\end{array}$ & $\begin{array}{l}t_{1}\left(\mathrm{~T}_{32} \mathrm{Q}_{4}\right): \text { Utilizar a congruência de triângulos. } \\
t_{2}\left(\mathrm{~T}_{32} \mathrm{Q}_{4}\right): \text { Apenas enunciar, sem demonstrar. } \\
t_{3}\left(\mathrm{~T}_{32} \mathrm{Q}_{4}\right): \text { Apresentar a propriedade como } \\
\text { exercício. }\end{array}$ \\
\hline
\end{tabular}

Fonte: Construção nossa 
$[\theta / \Theta]\left(\mathrm{T}_{2} \mathrm{Q}_{4}\right)$ : Os discursos teórico-tecnológicos associados à tarefa $\mathrm{T}_{2} \mathrm{Q}_{4}$ são: definição de retângulo, definição de diagonal de um quadrilátero, teorema das paralelas cortadas por uma transversal, propriedades do paralelogramo, definição de paralelogramo, soma dos ângulos internos de um quadrilátero e congruência de triângulos.

Ao optar pelas duas últimas técnicas de cada tarefa, o autor apenas enuncia a propriedade. Estas se distinguem pelo fato de, em cada tarefa, $t_{2}$ enunciar a propriedade na seção que contempla a teoria sobre quadriláteros e $t_{3}$ fazê-lo na seção de exercícios propostos ao aluno. Seguem-se as demonstrações, segundo as técnicas propostas para cada subtarefa.

\section{$T_{12} Q_{4}$ : Enunciar e demonstrar que todo retângulo é paralelogramo.}

As técnicas $t_{1}\left(\mathrm{~T}_{12} \mathrm{Q}_{4}\right)$ e $t_{2}\left(\mathrm{~T}_{12} \mathrm{Q}_{4}\right)$ se distinguem pelo fato de a primeira demonstrar a propriedade utilizando a definição de retângulo (os quatro ângulos iguais, consequentemente retos) e a propriedade das paralelas cortadas por uma transversal, enquanto a segunda utiliza a definição de retângulo e uma das condições necessárias e suficientes para que um quadrilátero seja paralelogramo (ângulos opostos congruentes ou ângulos consecutivos suplementares).

\section{$T_{22} Q_{4}$ : Enunciar e demonstrar que em todo retângulo as diagonais são congruentes.}

$t_{1}\left(\mathrm{~T}_{22} \mathrm{Q}_{4}\right)$ : Assumir que o retângulo é paralelogramo e utilizar congruência de triângulos.

Figura 16: Figura-suporte para a demonstração da tarefa $T_{22} Q_{4}$ segundo a técnica $t_{1}\left(T_{22} Q_{4}\right)$

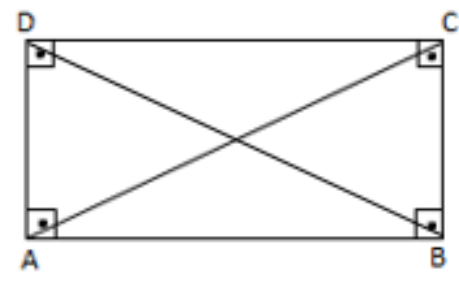

Fonte: Ferreira (2016, p.131).

Hipótese: $A B C D$ é um retângulo.

Tese: $A C=B D$

\section{Demonstração:}

Considerando os triângulos $A D B$ e $A B C$, tem-se:

$A D=B C$ (pois o retângulo é um paralelogramo)

$\operatorname{med}(D \hat{A} B)=90^{\circ}=\operatorname{med}(C \hat{B} A)(A B C D$ é retângulo $)$;

$\overline{A B}$ é lado comum.

Pelo caso de congruência lado-ângulo-lado, os triângulos $A D B$ e $A B C$ são congruentes. Logo $A C=B D$ 


\section{$T_{32} Q_{4}$ : Enunciar e demonstrar que todo paralelogramo que possui diagonais}

congruentes é um retângulo.

$t_{1}\left(\mathrm{~T}_{32} \mathrm{Q}_{4}\right)$ : Utilizar a congruência de triângulos.

Figura 17: Figura-suporte para a demonstração da tarefa T32Q4 segundo a técnica t1(T32Q4)

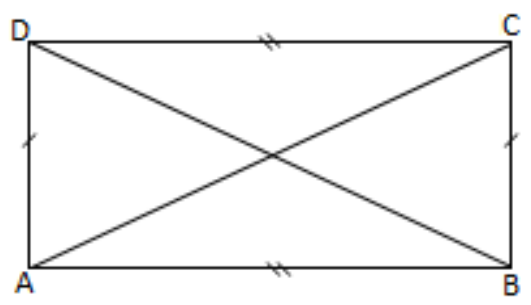

Fonte: Ferreira (2016, p.132).

Hipótese: $A B C D$ é um paralelogramo e $A C=B D$.

Tese: $A B C D$ é um retângulo.

\section{Demonstração:}

Considerando os triângulos $A D B$ e $A B C$, tem-se:

$A D=B C$ (pois $A B C D$ é um paralelogramo);

$A C=B D$ (hipótese);

$\overline{A B}$ é lado comum.

Pelo caso de congruência lado-lado-lado, os triângulos $A D B$ e $A B C$ são congruentes. Logo, $\operatorname{med}(D \hat{A} B)=\operatorname{med}(C \hat{B} A)$. Mas $A B C D$ é paralelogramo, e então $D \hat{A} B$ e $C \hat{B} A$ são suplementares. Assim, $\operatorname{med}(D \hat{A} B)=\operatorname{med}(C \hat{B} A)=90^{\circ}$. Mais uma vez, pelo fato de $A B C D$ ser um paralelogramo (os ângulos opostos são congruentes), tem-se que $\operatorname{med}(A \widehat{D} C)=$ med $(D \hat{C} B)=90^{\circ}$. Portanto $A B C D$ é um retângulo.

O Quadro 10 sumariza a análise da tarefa 2 da questão 4.

Quadro 10: Análise referente à tarefa 2 da questão 4

\begin{tabular}{|c|c|c|c|c|c|}
\hline & & & \multirow[b]{2}{*}{ LG1 } & \multirow[b]{2}{*}{ LG2 } & \\
\hline & & & & & LG3 \\
\hline \multirow{10}{*}{$\underset{\sim}{\stackrel{\overbrace{}}{d}}$} & \multirow{4}{*}{$\mathrm{T}_{12} \mathrm{Q}_{4}$} & $t_{1}\left(\mathrm{~T}_{12} \mathrm{Q}_{4}\right)$ & & & \\
\hline & & $t_{2}\left(\mathrm{~T}_{12} \mathrm{Q}_{4}\right)$ & & $\checkmark$ & \\
\hline & & $t_{3}\left(\mathrm{~T}_{12} \mathrm{Q}_{4}\right)$ & & & $\checkmark$ \\
\hline & & $t_{4}\left(\mathrm{~T}_{12} \mathrm{Q}_{4}\right)$ & $\checkmark$ & & \\
\hline & \multirow{3}{*}{$\mathrm{T}_{22} \mathrm{Q}_{4}$} & $t_{1}\left(\mathrm{~T}_{22} \mathrm{Q}_{4}\right)$ & & $\checkmark$ & \\
\hline & & $t_{2}\left(\mathrm{~T}_{22} \mathrm{Q}_{4}\right)$ & & & \\
\hline & & $t_{3}\left(\mathrm{~T}_{22} \mathrm{Q}_{4}\right)$ & $\begin{array}{llll} & \checkmark & & \end{array}$ & & \\
\hline & \multirow{3}{*}{$\mathrm{T}_{32} \mathrm{Q}_{4}$} & $t_{1}\left(\mathrm{~T}_{32} \mathrm{Q}_{4}\right)$ & & $\checkmark$ & \\
\hline & & $t_{2}\left(\mathrm{~T}_{32} \mathrm{Q}_{4}\right)$ & & & \\
\hline & & $t_{3}\left(\mathrm{~T}_{32} \mathrm{Q}_{4}\right)$ & $\checkmark$ & & \\
\hline
\end{tabular}

Fonte: Ferreira (2016, p.133). 
No quadro 11, apresentamos as subtarefas relacionadas à tarefa $\mathrm{T}_{3} \mathrm{Q}_{4} \mathrm{e}$ as técnicas que cumprem essa tarefa e subtarefas a ela relacionadas.

Quadro 11: Tarefa $\mathrm{T}_{3} \mathrm{Q}_{4}$ e as técnicas que cumprem essa tarefa e subtarefas a ela relacionadas

\begin{tabular}{|c|c|}
\hline Tarefas & Técnicas \\
\hline$T_{3} Q_{4}$ : Apresentar as propriedades do losango & 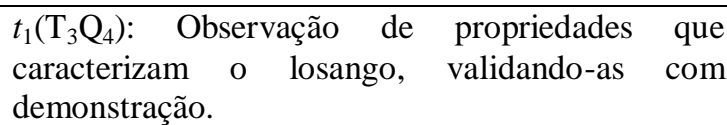 \\
\hline $\begin{array}{l}\mathrm{T}_{13} \mathrm{Q}_{4} \text { : Enunciar e demonstrar que todo losango } \\
\text { é paralelogramo }\end{array}$ & $\begin{array}{l}t_{1}\left(\mathrm{~T}_{13} \mathrm{Q}_{4}\right): \text { Utilizar a congruência de triângulos. } \\
t_{2}\left(\mathrm{~T}_{13} \mathrm{Q}_{4}\right): \text { Utilizar a congruência dos lados } \\
\text { opostos. } \\
t_{3}\left(\mathrm{~T}_{13} \mathrm{Q}_{4}\right) \text { : Apenas enunciar, sem demonstrar. } \\
t_{4}\left(\mathrm{~T}_{13} \mathrm{Q}_{4}\right): \text { Apresentar a propriedade como } \\
\text { exercício. }\end{array}$ \\
\hline $\begin{array}{l}\mathrm{T}_{23} \mathrm{Q}_{4}: \text { Enunciar e demonstrar que em todo } \\
\text { losango as diagonais são perpendiculares }\end{array}$ & $\begin{array}{l}t_{1}\left(\mathrm{~T}_{23} \mathrm{Q}_{4}\right) \text { : Assumir que o losango é paralelogramo } \\
\text { e utilizar a congruência de triângulos. } \\
t_{2}\left(\mathrm{~T}_{23} \mathrm{Q}_{4}\right) \text { : Apenas enunciar, sem demonstrar. } \\
t_{3}\left(\mathrm{~T}_{23} \mathrm{Q}_{4}\right) \text { : Apresentar a propriedade como } \\
\text { exercício. }\end{array}$ \\
\hline $\begin{array}{l}\mathrm{T}_{33} \mathrm{Q}_{4}: \text { Enunciar e demonstrar } \\
\text { paralelogramo que todo } \\
\text { perpendiculares é um losango }\end{array}$ & $\begin{array}{l}t_{1}\left(\mathrm{~T}_{33} \mathrm{Q}_{4}\right) \text { : Utilizar congruência de triângulos. } \\
t_{2}\left(\mathrm{~T}_{33} \mathrm{Q}_{4}\right) \text { : Apenas enunciar, sem demonstrar. } \\
t_{3}\left(\mathrm{~T}_{33} \mathrm{Q}_{4}\right): \text { Apresentar a propriedade como } \\
\text { exercício }\end{array}$ \\
\hline
\end{tabular}

Fonte: construção nossa

$[\theta / \Theta]\left(\mathrm{T}_{3} \mathrm{Q}_{4}\right)$ : $\mathrm{O}$ discurso teórico-tecnológico associado à tarefa $\mathrm{T}_{3} \mathrm{Q}_{4}$ consiste em: definição de losango, definição de diagonal de um quadrilátero, propriedades do paralelogramo, definição de paralelogramo, ângulos suplementares e congruência de triângulos.

As técnicas utilizadas para resolução de $\mathrm{T}_{3} \mathrm{Q}_{4}$ determinarão se a propriedade correspondente é contemplada na seção destinada à teoria ou na seção de exercício ou, ainda, se é apresentada a respectiva demonstração.

Seguem-se as técnicas apresentadas para a resolução das subtarefas referentes a $T_{3} Q_{4}$.

\section{$\mathrm{T}_{13} \mathrm{Q}_{4}$ : Enunciar e demonstrar que todo losango é paralelogramo.}

$t_{1}\left(\mathrm{~T}_{13} \mathrm{Q}_{4}\right)$ : Utilizar a congruência de triângulos.

Figura 18: Figura-suporte para a demonstração da tarefa $T_{32} Q_{4}$ segundo a técnica $t_{1}\left(T_{13} Q_{4}\right)$.

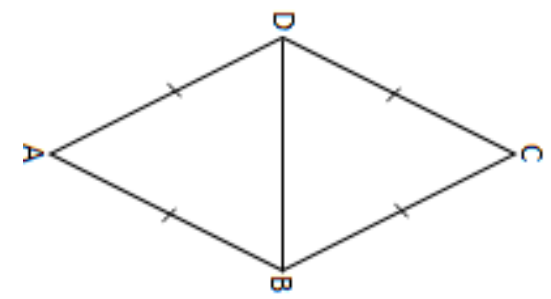

Fonte: Ferreira (2016, p.134).

Hipótese: $A B C D$ é um losango.

Tese: $A B C D$ é um paralelogramo.

Demonstração: 
Considerando os triângulos $A D B$ e $B C D$, tem-se que o lado $\overline{B D}$ é comum e que $A D=D C$ e $A B=B C$, visto que $A B C D$ é um losango. Pelo caso lado-lado-lado de congruência de triângulos, $A D B$ e $B C D$ são congruentes. Logo, $D \hat{A} B \equiv D \hat{C} B$ e, portanto, $A B C D$ é um paralelogramo.

Utilizando-se a técnica $t_{2}\left(T_{13} Q_{4}\right)$, basta usar a congruência dos lados opostos, que é uma condição necessária e suficiente para que um quadrilátero seja um paralelogramo.

$T_{23} Q_{4}$ : Enunciar e demonstrar que em todo losango as diagonais são perpendiculares. $\mathrm{t}_{1}\left(\mathrm{~T}_{23} \mathrm{Q}_{4}\right)$ : Assumir que o losango é paralelogramo e utilizar a congruência de triângulos.

Figura 19: Figura-suporte para a demonstração da tarefa $T_{32} Q_{4}$ segundo a técnica $t_{1}\left(T_{13} Q_{4}\right)$.

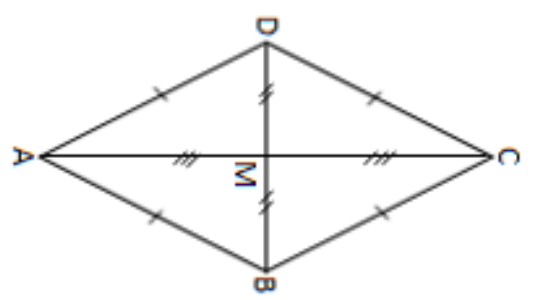

Fonte: Ferreira (2016, p.134).

Hipótese: $A B C D$ é um losango.

Tese: $\overline{A C}$ e $\overline{B D}$ são perpendiculares.

\section{Demonstração:}

Se $A B C D$ é losango, então $A B C D$ é paralelogramo. Daí segue-se que $D M=M B, A M=M C$ e $A B=B C=C D=D A$. Logo, os triângulos $A B M, B M C, M C D$ e $C M D$ são congruentes pelo caso lado-lado-lado e, portanto, $\operatorname{med}(A \widehat{M} D)=\operatorname{med}(A \widehat{M} B)=\operatorname{med}(B \widehat{M} C)=\operatorname{med}(C \widehat{M} D)=90^{\circ}$. Assim, podemos concluir que $\overline{A C}$ e $\overline{B D}$ são perpendiculares.

\section{$\mathrm{T}_{33} \mathrm{Q}_{4}$ : Enunciar e demonstrar que todo paralelogramo que possui diagonais perpendiculares é um losango.}

$t_{1}\left(\mathrm{~T}_{33} \mathrm{Q}_{4}\right)$ : Utilizar a congruência de triângulos.

Figura 20: Figura-suporte para a demonstração da tarefa $T_{33} Q_{4}$ segundo a técnica $t_{1}\left(T_{33} Q_{4}\right)$

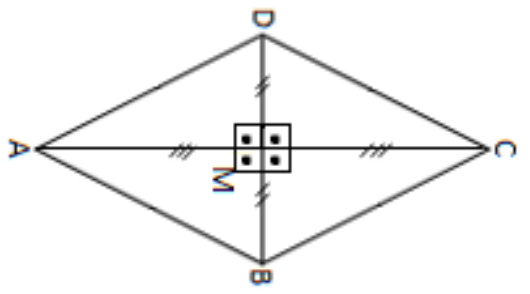

Fonte: Ferreira (2016, p.135).

Hipótese: $A B C D$ é um paralelogramo e $\overline{A C}$ e $\overline{B D}$ são perpendiculares. 
Tese: $A B C D$ é um losango.

\section{Demonstração:}

Como as diagonais de um paralelogramo se bisseccionam e, por hipótese, as diagonais do paralelogramo $A B C D$ são perpendiculares, podemos afirmar, pelo caso lado-ângulo-lado, que os triângulos $A M B, B M C, C M D$ e $D M A$ são congruentes. Logo, $A B=B C=C D=D A$ e, portanto, $A B C D$ é um losango.

No quadro 12 , a tarefa $\mathrm{T}_{4} \mathrm{Q}_{4}$ e as técnicas que cumprem essa tarefa.

Quadro 12: $\mathrm{T}_{4} \mathrm{Q}_{4}$ e técnicas relacionadas

\begin{tabular}{|l|l|}
\hline Tarefa & Técnicas \\
\hline $\mathbf{T}_{4} \mathbf{Q}_{4}:$ Enunciar e justificar que o quadrado é & $t_{1}\left(\mathbf{T}_{\mathbf{4}} \mathbf{Q}_{4}\right)$ : Utilizar as propriedades do \\
paralelogramo, retângulo e losango & paralelogramo, retângulo e losango. \\
& $t_{2}\left(\mathbf{T}_{4} \mathbf{Q}_{4}\right):$ Apresentar como exercício \\
\hline
\end{tabular}

Fonte: Construção nossa

$[\theta / \Theta]\left(\mathrm{T}_{4} \mathrm{Q}_{4}\right)$ : $\mathrm{O}$ discurso teórico-tecnológico associado à tarefa $\mathrm{T}_{4} \mathrm{Q}_{4}$ consiste em: definições de quadrado, paralelogramo, retângulo e losango; propriedades do paralelogramo, de retângulo e de losango.

No quadro 13, apresentamos as subtarefas relacionadas à tarefa $\mathrm{T}_{3} \mathrm{Q}_{4} \mathrm{e}$ as técnicas que cumprem essa tarefa e subtarefas a ela relacionadas

Quadro 13: $\mathrm{T}_{4} \mathrm{Q}_{4}$ - Subtarefas e técnicas relacionadas

\begin{tabular}{|c|c|}
\hline Tarefas & Técnicas \\
\hline $\mathrm{T}_{5} \mathrm{Q}_{4}$ : Apresentar as propriedades dos trapézios & 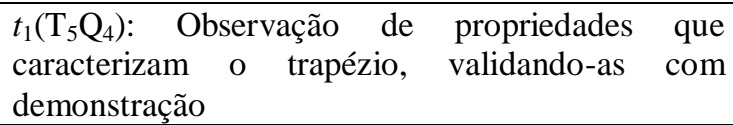 \\
\hline $\begin{array}{l}\mathrm{T}_{15} \mathrm{Q}_{4} \text { : Enunciar e demonstrar que os ângulos } \\
\text { consecutivos de bases distinta, de um trapézio } \\
\text { são suplementares }\end{array}$ & $\begin{array}{l}t_{1}\left(\mathrm{~T}_{15} \mathrm{Q}_{4}\right): \text { Utilizar a definição de trapézio e o } \\
\text { teorema das paralelas. } \\
t_{2}\left(\mathrm{~T}_{15} \mathrm{Q}_{4}\right): \text { Apenas enunciar, sem demonstrar. } \\
t_{3}\left(\mathrm{~T}_{15} \mathrm{Q}_{4}\right): \text { Apresentar a propriedade como } \\
\text { exercício }\end{array}$ \\
\hline $\begin{array}{l}\mathrm{T}_{25} \mathrm{Q}_{4} \text { : Enunciar e demonstrar que os ângulos } \\
\text { de cada base de um trapézio isósceles são } \\
\text { congruentes }\end{array}$ & $\begin{array}{l}t_{1}\left(\mathrm{~T}_{25} \mathrm{Q}_{4}\right) \text { : Utilizar a congruência de triângulos. } \\
t_{2}\left(\mathrm{~T}_{25} \mathrm{Q}_{4}\right): \text { Apenas enunciar, sem demonstrar. } \\
t_{3}\left(\mathrm{~T}_{25} \mathrm{Q}_{4}\right): \text { Apresentar a propriedade como } \\
\text { exercício }\end{array}$ \\
\hline $\begin{array}{l}\mathrm{T}_{35} \mathrm{Q}_{4} \text { : Enunciar e demonstrar que as diagonais } \\
\text { de um trapézio isósceles são congruentes. }\end{array}$ & $\begin{array}{l}t_{1}\left(\mathrm{~T}_{35} \mathrm{Q}_{4}\right): \text { Utilizar a congruência de triângulos. } \\
t_{2}\left(\mathrm{~T}_{35} \mathrm{Q}_{4}\right): \text { Apenas enunciar, sem demonstrar. } \\
t_{3}\left(\mathrm{~T}_{35} \mathrm{Q}_{4}\right): \text { Apresentar a propriedade como } \\
\text { exercício }\end{array}$ \\
\hline
\end{tabular}

Fonte: Construção nossa

$[\theta / \Theta]\left(\mathrm{T}_{5} \mathrm{Q}_{4}\right)$ : $\mathrm{O}$ discurso teórico-tecnológico associado à tarefa $\mathrm{T}_{5} \mathrm{Q}_{4}$ consiste em: definição de trapézio, definição de trapézio isósceles, definição de diagonal de um quadrilátero e congruência de triângulos, teorema das paralelas, definição de ângulos suplementares. 
As técnicas utilizadas para a resolução de $\mathrm{T}_{5} \mathrm{Q}_{4}$ determinam se a propriedade correspondente é contemplada na seção destinada à teoria ou na seção de exercício ou, ainda, se a respectiva demonstração.

Seguem-se as técnicas apresentadas para resolução das subtarefas referentes a $\mathrm{T}_{5} \mathrm{Q}_{4}$.

$T_{15} Q_{4}$ : Enunciar e demonstrar que os ângulos consecutivos de bases distintas de um trapézio são suplementares.

$t_{1}\left(\mathrm{~T}_{15} \mathrm{Q}_{4}\right)$ : Utilizar a definição de trapézio e o teorema das paralelas.

A solução dessa tarefa utilizando a técnica $t_{1}\left(\mathrm{~T}_{15} \mathrm{Q}_{4}\right)$ consiste em utilizar o teorema das paralelas e a definição de trapézio. Os ângulos consecutivos de bases distintas de um trapézio são colaterais internos formados por retas paralelas e uma transversal. Logo, são suplementares.

$T_{25} Q_{4}$ : Enunciar e demonstrar que os ângulos de cada base de um trapézio isósceles são congruentes.

$t_{1}\left(\mathrm{~T}_{25} \mathrm{Q}_{4}\right)$ : Utilizar a congruência de triângulos.

Figura 21: Figura-suporte para a demonstração da tarefa $T_{15} Q_{4}$ segundo a técnica $t_{1}\left(T_{15} Q_{4}\right)$.

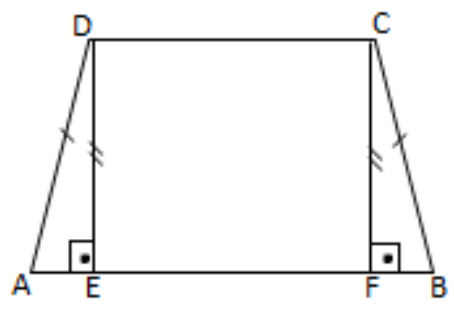

Fonte: Ferreira (2016, p.137).

Hipótese: $A B C D$ é um trapézio isósceles.

Tese: $D \hat{A} B \equiv C \widehat{B} A$ e $A \widehat{D} C \equiv D \hat{C} B$.

\section{Demonstração:}

Traçando duas perpendiculares à base maior do trapézio pelos pontos $C$ e $D$ (Figura 32), obtemos os triângulos retângulos $A D E$ e $B C F$ tais que:

$A D=B C(A B C D$ é um trapézio isósceles $) ;$

$D E=C F$ (distâncias entre duas paralelas, que corresponde à altura do trapézio).

Pelo caso cateto-hipotenusa, $A D E$ e $B C F$ são congruentes. Logo, $D \hat{A} B \equiv C \hat{B} A$. Como os ângulos $A \widehat{D} C$ e $D \hat{C} B$ são respectivamente suplementos de $D \hat{A} B$ e $C \hat{B} A$, então $A \widehat{D} C \equiv D \hat{C} B$. $\mathrm{T}_{35} \mathrm{Q}_{4}$ : Enunciar e demonstrar que as diagonais de um trapézio isósceles são congruentes.

$t_{1}\left(\mathrm{~T}_{35} \mathrm{Q}_{4}\right)$ : Utilizar a congruência de triângulos. 
Figura 22: Figura-suporte para a demonstração da tarefa $T_{25} Q_{4}$ segundo a técnica $t_{1}\left(T_{25} Q_{4}\right)$.

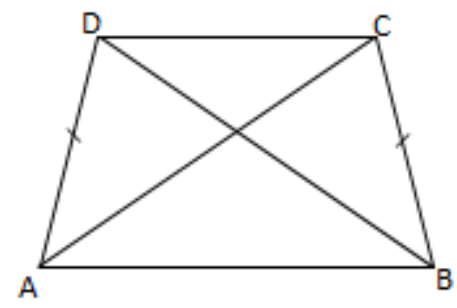

Fonte: Ferreira (2016, p.138).

Hipótese: $A B C D$ é um trapézio isósceles.

Tese: $A C=B D$.

\section{Demonstração:}

Considerando os triângulos $A C D$ e $B D C$, tem-se que:

$A D=B C$ (lados congruentes do trapézio isósceles);

$A \widehat{D} C \equiv D \hat{C} B$ (ângulos da base de um trapézio isósceles);

$\overline{D C}$ é lado comum.

Pelo caso de congruência lado-ângulo-lado, os triângulos $A C D$ e $B D C$ são congruentes. Logo, $A C=B D$.

As técnicas $t_{1}\left(\mathrm{~T}_{15} \mathrm{Q}_{4}\right)$ e $t_{1}\left(\mathrm{~T}_{25} \mathrm{Q}_{4}\right)$ só têm validade para trapézios não paralelogramos. Embora os paralelogramos sejam trapézios com dois lados não bases congruentes, deve ser feita uma restrição quanto à definição de trapézio isósceles, para não haver incoerências nas propriedades desse tipo de trapézio. Uma definição sugerida por Bongiovanni (2010, p. 10) e que evita tais contradições é: "Trapézio isósceles é um trapézio que tem um único par de lados opostos congruentes (ou de uma maneira equivalente: trapézio isósceles é um trapézio que apresenta um único eixo de simetria)".

Dissertamos a seguir sobre a questão 5, as tarefas e as técnicas a elas relacionadas:

\section{Questão $5\left(Q_{5}\right)$ : Como o autor aborda base média de um triângulo?}

\section{$T_{1} Q_{5}:$ Enunciar e demonstrar o teorema da base média do triângulo.}

$t_{1}\left(\mathrm{~T}_{1} \mathrm{Q}_{5}\right)$ : Utilizar o teorema das paralelas, a congruência de triângulos e o axioma de Euclides. $t_{2}\left(\mathrm{~T}_{1} \mathrm{Q}_{5}\right)$ : Utilizar o teorema das paralelas, congruência de triângulos e a existência do ponto médio.

$t_{3}\left(\mathrm{~T}_{1} \mathrm{Q}_{5}\right)$ : Apenas enunciar sem demonstrar.

$t_{4}\left(\mathrm{~T}_{1} \mathrm{Q}_{5}\right)$ : Apresentar o teorema como exercício. 
$[\theta / \Theta]\left(\mathrm{T}_{1} \mathrm{Q}_{5}\right)$ : $\mathrm{O}$ discurso teórico-tecnológico associado à tarefa $\mathrm{T}_{1} \mathrm{Q}_{5}$ consiste em: definição de paralelogramo, propriedades do paralelogramo, definição de ponto médio, axioma de Euclides, teorema das paralelas e congruência de triângulos.

Segue-se a resolução da tarefa $\mathrm{T}_{1} \mathrm{Q}_{5}$ segundo as técnicas $t_{1}\left(\mathrm{~T}_{1} \mathrm{Q}_{5}\right)$ e $t_{2}\left(\mathrm{~T}_{1} \mathrm{Q}_{5}\right)$.

Figura 23: Figura-suporte para a demonstração da tarefa $T_{1} Q_{5}$ segundo as técnicas $t_{1}\left(T_{1} Q_{5}\right)$ e $t_{2}\left(T_{1} Q_{5}\right)$.

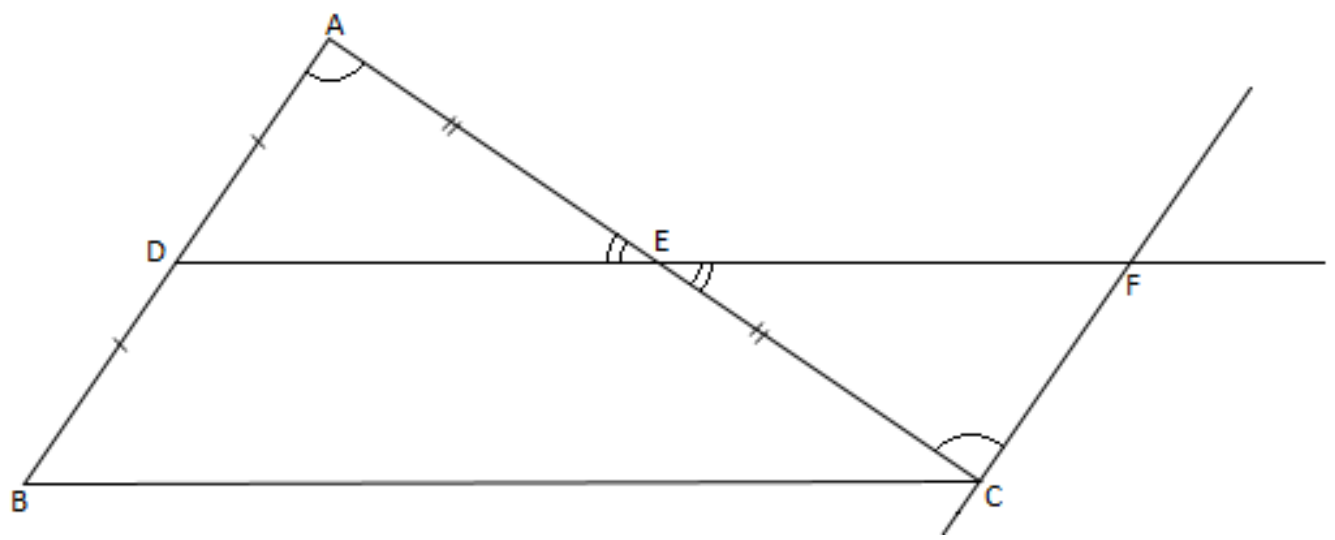

Fonte: Ferreira (2016, p.139).

Hipótese: $D$ é ponto médio de $\overline{A B}$ e $E$ é ponto médio de $\overline{A C}$.

Tese: $\overline{D E} / / \overline{B C}$ e $D E=\frac{B C}{2}$.

Pelo vértice $C$ do triângulo $A B C$, traça-se uma reta paralela ao lado $\overline{A B}$ (a existência dessa reta está garantida pelo axioma de Euclides), a qual que encontra a reta-suporte do segmento $\overline{D E}$ em um ponto $F$.

Considerando os triângulos $A D E$ e $C E F$ tem-se que:

$D \hat{A} E \equiv E \hat{C} F$ (ângulos alternos internos);

$A E \equiv E C(E$ é ponto médio do lado $\overline{A C})$;

$D \widehat{E} A \equiv C \widehat{E} F$ (ângulos opostos pelo vértice).

Pelo caso de congruência ângulo-lado-ângulo, os triângulos $A D E$ e $C E F$ são congruentes. Logo, $A D=C F=B D$. Segue-se então que o quadrilátero $B C F D$ possui dois lados paralelos e congruentes. Assim, $B C F D$ é um paralelogramo e, portanto, $\overline{D E} / \overline{B C}$.

Ainda da congruência dos triângulos $A D E$ e $C E F$, tem-se que $D E=E F$ e $D F=B C$. Logo. $D E=\frac{1}{2} B C$.

A técnica $t_{2}\left(\mathrm{~T}_{1} \mathrm{Q}_{5}\right)$ se diferencia de $t_{1}\left(\mathrm{~T}_{1} \mathrm{Q}_{5}\right)$ ao utilizar a existência do ponto médio, em vez de usar o axioma de Euclides, ou seja, considerar um ponto $F$ na reta-suporte do segmento $\overline{D E}$ tal que $E$ seja ponto médio de $\overline{D E}$ e obter o paralelismo entre $\overline{A B}$ e $\overline{C F}$ a partir da congruência 
dos triângulos $A D E$ e $C E F$. Desse modo, a congruência se justifica pelo caso lado-ângulolado.

O Quadro 16 sumariza a análise das tarefas 3, 4 e 5 da questão 4 e da tarefa 1 da questão 5.

Quadro 14: Análise referente às tarefas 3,4 e 5 da questão 4 e tarefa 1 da questão 5

\begin{tabular}{|c|c|c|c|c|c|}
\hline & & & & & \\
\hline & & & LG1 & LG2 & LG3 \\
\hline \multirow{10}{*}{ 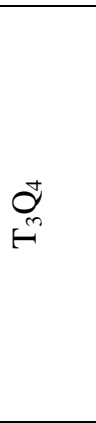 } & \multirow{4}{*}{$\mathrm{T}_{13} \mathrm{Q}_{4}$} & $t_{1}\left(\mathrm{~T}_{13} \mathrm{Q}_{4}\right)$ & & & \\
\hline & & $t_{2}\left(\mathrm{~T}_{13} \mathrm{Q}_{4}\right)$ & & $\checkmark$ & \\
\hline & & $t_{3}\left(\mathrm{~T}_{13} \mathrm{Q}_{4}\right)$ & & & $\checkmark$ \\
\hline & & $t_{4}\left(\mathrm{~T}_{13} \mathrm{Q}_{4}\right)$ & $\checkmark$ & & \\
\hline & \multirow{3}{*}{$\mathrm{T}_{23} \mathrm{Q}_{4}$} & $t_{1}\left(\mathrm{~T}_{23} \mathrm{Q}_{4}\right)$ & & $\checkmark$ & \\
\hline & & $t_{2}\left(\mathrm{~T}_{23} \mathrm{Q}_{4}\right)$ & & & $\checkmark$ \\
\hline & & $t_{3}\left(\mathrm{~T}_{23} \mathrm{Q}_{4}\right)$ & $\checkmark$ & & \\
\hline & \multirow{3}{*}{$\mathrm{T}_{33} \mathrm{Q}_{4}$} & $t_{1}\left(\mathrm{~T}_{33} \mathrm{Q}_{4}\right)$ & & $\checkmark$ & \\
\hline & & $t_{2}\left(\mathrm{~T}_{33} \mathrm{Q}_{4}\right)$ & & & $\checkmark$ \\
\hline & & $t_{3}\left(\mathrm{~T}_{33} \mathrm{Q}_{4}\right)$ & $\checkmark$ & & \\
\hline \multirow{2}{*}{$\stackrel{d}{ \pm}$} & \multirow[b]{2}{*}{-} & $t_{1}\left(\mathrm{~T}_{4} \mathrm{Q}_{4}\right)$ & & $\checkmark$ & \\
\hline & & $t_{2}\left(\mathrm{~T}_{4} \mathrm{Q}_{4}\right)$ & $\checkmark$ & & \\
\hline \multirow{10}{*}{$\underset{\stackrel{d}{*}}{\stackrel{d}{r}}$} & \multirow{3}{*}{$\mathrm{T}_{15} \mathrm{Q}_{4}$} & $t_{1}\left(\mathrm{~T}_{15} \mathrm{Q}_{4}\right)$ & & $\checkmark$ & \\
\hline & & $t_{2}\left(\mathrm{~T}_{15} \mathrm{Q}_{4}\right)$ & & & \\
\hline & & $t_{3}\left(\mathrm{~T}_{15} \mathrm{Q}_{4}\right)$ & & & \\
\hline & \multirow{3}{*}{$\mathrm{T}_{25} \mathrm{Q}_{4}$} & $t_{1}\left(\mathrm{~T}_{25} \mathrm{Q}_{4}\right)$ & & $\checkmark$ & \\
\hline & & $t_{2}\left(\mathrm{~T}_{25} \mathrm{Q}_{4}\right)$ & & & \\
\hline & & $t_{3}\left(\mathrm{~T}_{25} \mathrm{Q}_{4}\right)$ & $\checkmark$ & & $\checkmark$ \\
\hline & \multirow{4}{*}{$\mathrm{T}_{35} \mathrm{Q}_{4}$} & $t_{1}\left(\mathrm{~T}_{35} \mathrm{Q}_{4}\right)$ & & $\checkmark$ & \\
\hline & & $t_{2}\left(\mathrm{~T}_{35} \mathrm{Q}_{4}\right)$ & & & \\
\hline & & $t_{3}\left(\mathrm{~T}_{35} \mathrm{Q}_{4}\right)$ & $\checkmark$ & & \\
\hline & & $t_{4}\left(\mathrm{~T}_{35} \mathrm{Q}_{4}\right)$ & & & \\
\hline \multirow{4}{*}{ 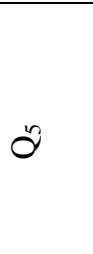 } & \multirow{4}{*}{$\mathrm{T}_{1} \mathrm{Q}_{5}$} & $t_{1}\left(\mathrm{~T}_{1} \mathrm{Q}_{5}\right)$ & & $\checkmark$ & \\
\hline & & $t_{2}\left(\mathrm{~T}_{1} \mathrm{Q}_{5}\right)$ & $\checkmark$ & & $\checkmark$ \\
\hline & & $t_{3}\left(\mathrm{~T}_{1} \mathrm{Q}_{5}\right)$ & & & \\
\hline & & $t_{4}\left(\mathrm{~T}_{1} \mathrm{Q}_{5}\right)$ & & & \\
\hline
\end{tabular}

Fonte: Ferreira (2016, p.140).

A classificação dos quadriláteros é abordada nos três livros analisados. Em LG1, apenas o paralelogramo é definido na seção que focaliza a teoria. Os demais quadriláteros (retângulo, losango, quadrado, trapézio) são definidos na seção de exercícios. Semelhantemente, as propriedades desses quadriláteros e as relações entre eles são em sua maioria expostas como exercício na seção referente à teoria ou propostas como exercício nas seções Exercício ou Problemas. Essa forma de apresentação pode levar a uma abordagem superficial desse tópico e evidencia que o autor admite que o conteúdo já é conhecido pelo aluno. 
As únicas propriedades de quadriláteros demonstradas pelo autor são as relativas às tarefas $\mathrm{T}_{31} \mathrm{Q}_{4}, \mathrm{~T}_{41} \mathrm{Q}_{4}$ e $\mathrm{T}_{1} \mathrm{Q}_{5}$. As duas primeiras são executadas respectivamente pelas técnicas $t_{1}\left(\mathrm{~T}_{31} \mathrm{Q}_{4}\right)$ e $t_{1}\left(\mathrm{~T}_{41} \mathrm{Q}_{4}\right)$. Apenas em $\mathrm{T}_{31} \mathrm{Q}_{4}$ foram utilizadas uma representação figural e uma reconfiguração por meio da diagonal do paralelogramo, embora sem um tratamento que colabore com a associação entre a apreensão perceptiva e a discursiva, pois não estão evidenciados na figura os ângulos internos dos triângulos obtidos na reconfiguração, nem as congruências entre esses ângulos. $\mathrm{O}$ autor não aborda essas duas propriedades em um único teorema, na forma 'se, e somente se'.

$\mathrm{T}_{1} \mathrm{Q}_{5}$ é executada pelo autor de LG1 mediante a técnica $t_{1}\left(\mathrm{~T}_{1} \mathrm{Q}_{5}\right)$. É realizada uma reconfiguração do triângulo como apresentado na Figura 34, porém, mais uma vez, não é feito um tratamento figural coerente com o tratamento discursivo. Duval (2012) enfatiza a importância da figura como apoio ao raciocínio dedutivo.

As validações das propriedades de quadriláteros utilizadas em LG1 são do tipo conceitual (BALACHEFF, 1988) e são priorizados os registros em língua natural e simbólicos.

Em LG2 são apresentadas as definições de todos os quadriláteros (paralelogramo, losango, retângulo, quadrado e trapézio) na seção destinada à teoria e todas as propriedades são enunciadas e validadas por meio de provas conceituais. (BALACHEFF, 1988). Para enunciar as propriedades e definições dos quadriláteros, o autor utiliza os três registros de representação: língua natural, simbólico e figural.

Mesmo sendo um livro voltado ao ensino médio, as demonstrações das propriedades não são precedidas de atividades de argumentação ou outras que levem o aluno a conjecturar e sentirse desafiado a justificar as propriedades.

Os autores de LG2 utilizam a figura como apoio às demonstrações das propriedades dos paralelogramos, losango, retângulo e quadrado, efetuando tratamentos figurais que interagem com o tratamento discursivo, o que pode favorecer uma associação entre a apreensão perceptiva e a discursiva.

Ainda em LG2, as propriedades que caracterizam os quadriláteros paralelogramo, losango, retângulo, quadrado, não são enunciadas em um único teorema, ou seja, na forma 'se, e somente se'. Os autores fazem um resumo das condições necessárias (relativas às diagonais) para que um quadrilátero convexo seja paralelogramo, losango, retângulo ou quadrado, mas não enfatizam que estas são também suficientes e que, portanto, podem caracterizar cada um desses quadriláteros. A Figura 24 sumariza essas condições apresentadas em LG2. 
Figura 24: Resumo das condições necessárias para que um quadrilátero seja paralelogramo, retângulo, losango e quadrado.

Notemos, em resumo, que se um quadrilátero convexo
tem as diagonais que se cortam ao meio, então é um paralelogramo,
tem diagonais que se cortam ao meio e são congruentes, então é um retângulo,
tem diagonais que se cortam ao meio e são perpendiculares, então é um losango,
tem diagonais que se cortam ao meio, são congruentes e são perpendiculares,
então é um quadrado.

Fonte: LG2 (p. 110, apud FERREIRA, 2016, p.142).

Em LG3, os quadriláteros são classificados na seção destinada à teoria e não são utilizadas condições mínimas nas definições de losango, retângulo e quadrado. O losango, por exemplo, é definido como "um paralelogramo cujos lados são congruentes". (LG3, p. 61) Nesse caso, a palavra 'paralelogramo' é desnecessária, uma vez que pode ser provado que todo losango é paralelogramo.

Nesse livro, a única propriedade relacionada ao objeto quadrilátero que é demonstrada é o teorema da base média do triângulo $\left(\mathrm{T}_{1} \mathrm{Q}_{6}\right)$. É utilizada a técnica $t_{2}\left(\mathrm{~T}_{1} \mathrm{Q}_{5}\right) \mathrm{e}$, como apoio à demonstração, é efetuada uma reconfiguração do triângulo por meio de uma paralela a um de seus lados, de modo semelhante ao da Figura 35. O tratamento figural utilizado é coerente com o tratamento do discurso em língua natural. Os registros utilizados por estes autores são figurais, língua natural e simbólico.

O conteúdo 'quadriláteros' é apresentado em LG1, LG2 e LG3 de forma semelhante. Como previsto, em todos eles as provas apresentadas são formais, com a exclusiva função de explicação. As propriedades são abordadas de modo direto sem nenhuma atividade que permita ao aluno fazer conjecturas ou sentir a necessidade de demonstrá-las.

LG1 e LG3 se assemelham por não validarem a maioria das propriedades dos quadriláteros. Não supomos que esses autores considerem desnecessária a validação matemática dessas propriedades, mas sim que não as demonstram por acreditarem que são elementares para o nível a que o livro é destinado.

\section{Considerações sobre a análise dos livros didáticos}

Propusemo-nos neste artigo a estudar as organizações didáticas e matemáticas relacionadas ao tema 'quadriláteros' em três livros adotados em cursos de licenciatura em matemática no Brasil.

Nossa análise foi desenvolvida segundo a teoria antropológica do didático, de Chevallard (1999), e a teoria dos registros de representação semiótica, de Duval, e adotamos a tipologia 
de provas proposta por Balacheff (1988). Portanto, quando nesta análise nos referirmos a provas conceituais, falamos das demonstrações que, conforme esse pesquisador, tratam de uma série de enunciados que se organizam segundo um conjunto bem definido de regras.

Iniciamos nossa análise investigando sobre o que esses livros apresentam com relação à história e quanto ao que vem a ser o método dedutivo e seus termos próprios. Observamos que os três livros trazem textos que tratam da história da matemática, porém nenhum destes é usado como motivação para se introduzirem conteúdos específicos.

Quanto ao método dedutivo, LG1 e LG3 trazem dele alguma noção, sendo que LG1 traz essa informação após já havê-lo introduzido. Os termos 'prova' e ‘demonstração' são utilizados nos três livros como sinônimos e estes não são abordados como objeto de estudo, mas exclusivamente com função de validação.

Os três livros desenvolvem o conteúdo 'quadriláteros' de forma semelhante. A abordagem dos conceitos e propriedades é direta, sem utilização de nenhum recurso que leve o aluno a fazer conjecturas. Em vez disso, procedem à formalização, seguida da resolução de problemas.

Em LG1 e LG3, o conteúdo 'quadriláteros' é abordado a título de revisão, sem um capítulo específico destinado a seu estudo e com poucas demonstrações realizadas pelos autores, sendo a maioria deixada como exercício para o aluno. Em LG2, um capítulo é dedicado ao estudo dos quadriláteros. As propriedades são demonstradas e as definições e propriedades são enunciadas simultaneamente nos três registros de representação.

Quanto às tarefas propostas para o aluno, LG3 combina aquelas em que há reprodução de técnica e tarefas que exigem interpretação, para depois aplicar a técnica e tarefas de realização de provas. Em LG1 e LG3 predominam as tarefas de realização de provas, sendo estas em um número reduzido, prevalecendo, na seção de exercícios, a complementação da teoria.

Nos três livros analisados, as definições de trapézio e de trapézio isósceles adotadas são incoerentes com as propriedades enunciadas, sendo aconselhável fazer uma restrição quanto à definição de trapézio isósceles para adequação aos resultados considerados.

As organizações didáticas dos três livros analisados apresentam semelhanças, especialmente em LG1 e LG3. O conteúdo ‘quadriláteros’ é apresentado de forma direta e superficial. Visto que o livro é uma ferramenta de apoio importante para alunos e professores e que a realidade evidenciada em pesquisas (SANTOS, 2005; CURI, 2004) é a de que os alunos ingressos em cursos de licenciatura em matemática têm formação geométrica precária, podemos afirmar que a forma como o conteúdo 'quadriláteros' é apresentado nesses livros pode contribuir para as dificuldades apresentadas pelos alunos na aprendizagem desse conteúdo.

A geometria é geralmente uma disciplina oferecida nos primeiros semestres da graduação, tipicamente constituindo o primeiro contato do aluno com o método dedutivo. Os alunos iniciam o uso desse método sem saber do que se tata ou como funciona. Diante desse fato, 
seria coerente que nos livros de geometria, especialmente os voltados à graduação, esclarecessem o que vem a ser o método dedutivo e seus termos próprios antes de introduzilo.

Os livros analisados são adotados no ensino superior, o que demanda destes uma abordagem científica. Logo, não esperávamos desses livros validações empíricas para as propriedades apresentadas. No entanto, a forma como o conteúdo é introduzido é outro ponto que merece reflexão. A inclusão de situações em forma problemas de construção geométrica, que levem o aluno a fazer descobertas seria um caminho a ser considerado. Caberia mudar o trajeto adotado na maioria dos livros, e reproduzido por professores, que vai da formalização para a aplicação de resultados na resolução de problemas, adotando, ao invés, uma abordagem inversa: partir da situação-problema e culminar na institucionalização.

As observações advindas da análise dos livros selecionados, comparadas aos resultados obtidos na análise do questionário e fundamentadas pela revisão de literatura, nos permitiram chegar a alguns resultados que foram fundamentais para o processo de construção da organização didática que é o objetivo principal de nossa tese.

\section{Referências}

BALACHEFF, N. Aspects of proof in pupil's practice of school mathematics. In: PIMM, D. (Ed.). Mathematics Teachers and Children. London: Hodder and Stoughton, 1988, p. 216-235.

BALACHEFF, N. Procesos de prueba en los alumnos de matemáticas (Trad. Pedro Gómez). Bogotá, Colombia: Universidad de los Andes, 2000. Disponível em <http://hal.archivesouvertes.fr/docs/00/52/01/33/PDF/Balacheff2000Proceso.pdf >. Data do acesso: 12 de Janeiro de 2013.

BALACHEFF, N. The researcher epistemology: a deadlock for educational research on proof. Les Cahiers du Laboratoire Leibniz, n. 109, Grenoble, 2004. Disponível em: < http://wwwleibniz.imag.fr/LesCahiers/>. Data do acesso: 12 de janeiro de 2013

BALACHEFF, N. Bridging knowing and proving in mathematics: A didactical perspective. In G. Hanna, H. N. Jahnke \& H. Pulte (Eds.), Explanation and Proof in Mathematics. Philosophical and Educational Perspectives (pp. 115-136). New York: Springer, 2010. Disponível em: <http://link.springer.com/chapter/10.1007/978-1-4419-0576-5_9\#page-2>. Acesso em 12 de janeiro de 2013.

BARBOSA, J.L.M. Geometria Euclidiana Plana. 8 ed. Rio de Janeiro: IMPA, 2006.

BONGIOVANNI, V. As diferentes definições dos quadriláteros notáveis. Revista do Professor de Matemática. São Paulo: IME-USP, n. 55, p. 29-32, 2004.

BONGIOVANNI, V. Sobre definições de trapézio isósceles. Revista do professor de Matemática, São Paulo: IME-USP, n. 72, p. 9-10, 2010.

CHEVALLARD, Yves. El análisis de las prácticas docentes en la teoria antropológica de lo didáctico. Recherches en Didactique des Mathématiques, v. 19, n.2, p. 221-266, 1999.

CURI, E. Formação de professores polivalentes: uma análise de conhecimentos para ensinar Matemática e de crenças e atitudes que interferem na construção desse conhecimento. 2004. 278f. 
Tese (Doutorado em Educação Matemática) - Pontifícia Universidade Católica, São Paulo, São Paulo, 2004

DOLCE, O.; POMPEO, J.N. Fundamentos de Matemática Elementar. 7 ed. v. 9. São Paulo: Atual, 2009.

DOMINGUES, H.H. A Demonstração ao longo dos séculos. Bolema, Rio Claro, ano 15, n.18, p.4655,2002 .

DUVAL, R. Registros de representações semióticas e funcionamento cognitivo da compreensão em matemática In: MACHADO, S. D. A. (Org.). Aprendizagem em Matemática: registros de representação semiótica. Campinas, SP: Papirus, 2009a. p. 11-33.

DUVAL, R., Semiósis e Pensamento Humano: Registros Semióticos e Aprendizagens Intelectuais. Coleção Contexto da Ciência. São Paulo: Livraria Editora da Física, 2009b.

DUVAL, R. Ver e ensinar a Matemática de outra forma: entrar no modo matemático de pensar: os registros de representação semióticas. 1 ed. São Paulo: PROEM, 2011.

DUVAL, R. Abordagem cognitiva de problemas de geometria em termos de congruência. Tradução: Méricles Thadeu Moretti, Revemat: R. Eletr. de Edu. Matem. ISSN 1981-1322. Florianópolis, v. 7, n. 1, p.118-138, 2012.

JAHNKE, H.N. Theorems that admit exceptions, including a remark on Toulmin. ZDM, Essen, Germany, v. 40, n. 3, p. 363-371, 2008.

MAIOLI, M. Uma oficina para formação de professores com enfoque em quadriláteros, 2002, 162f. Dissertação (Mestrado) - Pontifícia Universidade Católica de São Paulo, São Paulo, 2001.

MELLO, Elizabeth G. S. da. Demonstração: uma sequência didática para a introdução de seu aprendizado no ensino de geometri". Dissertação (Mestrado em Educação Matemática), 187p,

ORDEM, J. Prova e demonstração em geometria plana: concepções de estudantes da licenciatura em ensino de matemática em Moçambique. Tese (Doutorado) 325p. - Pontifícia Universidade Católica de São Paulo, São Paulo, 2015.

REZENDE, E.Q.; QUEIROZ, M.L.B. Geometria Euclidiana Plana e Construções Geométricas. Campinas: Editora Unicamp, 2008.

SANTOS, R.C. Conteúdos Matemáticos na Educação Básica e sua abordagem em cursos de Licenciatura em Matemática, 2005, 234f. Dissertação (Mestrado em Educação Matemática) Pontifícia Universidade Católica de São Paulo, São Paulo, 2001.

SILVA, Alvesmar Ferreira da. Desenvolvimento de uma sequência didática sobre quadriláteros e suas propriedades: contribuições de um grupo colaborativo. Dissertação (Mestrado em Educação Matemática), 93p, Pontifícia Universidade Católica de São Paulo, São Paulo, 2007.

Recebido em 24/10/2017 - Aceito em 31/10/2017. 